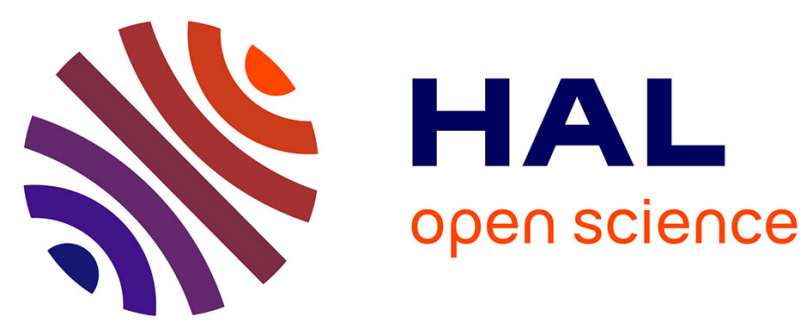

\title{
Multi-annual monitoring of the water vapor vertical distribution on Mars by SPICAM on Mars Express
}

Anna Fedorova, Franck Montmessin, Oleg Korablev, Franck Lefèvre, Alexander Trokhimovskiy, Jean-Loup Bertaux

\section{- To cite this version:}

Anna Fedorova, Franck Montmessin, Oleg Korablev, Franck Lefèvre, Alexander Trokhimovskiy, et al.. Multi-annual monitoring of the water vapor vertical distribution on Mars by SPICAM on Mars Express. Journal of Geophysical Research. Planets, 2021, 126 (1), pp.e2020JE006616. 10.1029/2020JE006616 . insu-03059010

\section{HAL Id: insu-03059010 https://hal-insu.archives-ouvertes.fr/insu-03059010}

Submitted on 2 Aug 2021

HAL is a multi-disciplinary open access archive for the deposit and dissemination of scientific research documents, whether they are published or not. The documents may come from teaching and research institutions in France or abroad, or from public or private research centers.
L'archive ouverte pluridisciplinaire HAL, est destinée au dépôt et à la diffusion de documents scientifiques de niveau recherche, publiés ou non, émanant des établissements d'enseignement et de recherche français ou étrangers, des laboratoires publics ou privés. 


\title{
JGR Planets
}

\section{RESEARCH ARTICLE \\ 10.1029/2020JE006616 \\ Multi-Annual Monitoring of the Water Vapor Vertical Distribution on Mars by SPICAM on Mars Express}

Key Points:

- Through 8 Martian years observed by SPICAM $\mathrm{H}_{2} \mathrm{O}$ regularly reaches $40-60 \mathrm{~km}$ in the aphelion season and $70-90 \mathrm{~km}$ in the perihelion season

- In southern summer, large $\mathrm{H}_{2} \mathrm{O}$ vmrs $(\sim 100 \mathrm{ppm})$ are repeatedly observed up to $80 \mathrm{~km}$, confirming a seasonal impact on the hydrogen escape rate

- Out of the two observed GDS, in MY28 and MY34, the GDS of MY28, coincident with the southern summer solstice, shows a larger water increase

Correspondence to:

A. Fedorova,

fedorova@iki.rssi.ru

Citation:

Fedorova, A., Montmessin, F., Korablev,

O., Lefèvre, F., Trokhimovskiy, A., \&

Bertaux, J. L. (2021). Multi-annual monitoring of the water vapor vertical distribution on Mars by SPICAM on Mars Express. Journal of Geophysical Research: Planets, 126, e2020JE006616. https://doi.org/10.1029/2020JE006616

Received 9 JUL 2020

Accepted 7 DEC 2020

(C) 2020. American Geophysical Union. All Rights Reserved.

\author{
Anna Fedorova $^{1}$ (D), Franck Montmessin ${ }^{2}$ (D), Oleg Korablev ${ }^{1}$ (D) Franck Lefèvre ${ }^{2}$ (D), \\ Alexander Trokhimovskiy ${ }^{1}$ (D), and Jean-Loup Bertaux ${ }^{2}$ (D)

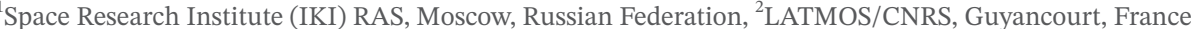

Abstract The distribution of water vapor with altitude has long remained a missing piece of the observational data set of water vapor on Mars. In this study, we present the first multi-annual survey of water vapor profile covering the altitude range from 0 to $100 \mathrm{~km}$ based on the SPICAM/Mars Express occultation measurements. During the aphelion season, water remains confined below 40-60 km for all Martian years observed. The highest altitude where water vapor can be spotted is between 70 and $90 \mathrm{~km}$ during the southern summer ( $L s=240-300^{\circ}$; perihelion season), approaching the transition between the middle and upper atmosphere. In this season, years without a global dust storm (GDS) show a significant moistening of the upper atmosphere ( $\sim 100 \mathrm{ppmv})$ in the southern hemisphere, confirming a seasonal impact on the hydrogen escape rate. The two observed GDS, in MY28 and MY34, show a substantial disparity in water vapor response. The storm in MY28, which coincides with the southern summer solstice, creates the largest excess of water in both hemispheres at $>80 \mathrm{~km}$. This climatology of water vapor will supply a robust statistical basis to address the long-term escape processes of water from Mars.

Plain Language Summary The vertical distribution of water vapor in the Martian atmosphere is key to understanding water transport and its escape from the planet, which in turn helps to explain the fate of water through Mars' history. Recent studies suggest that the transport of water to $80 \mathrm{~km}$ can increase the hydrogen escape rate by an order of magnitude and provide evidence for the role of global dust storms (GDS) in the regulation of this process. We monitored the vertical water distribution during multiple Martian years for the first time, including two years with GDSs. We confirm the efficiency of GDS in delivering water to $80 \mathrm{~km}$ and emphasize the role of a regular perihelion season, which raises the water in the southern hemisphere every year. The MY28 GDS, coincident with the southern summer solstice, demonstrated the most massive increase of water abundances at high altitudes through the observed years.

\section{Introduction}

Despite the scarcity of water vapor in the Martian atmosphere it nonetheless plays a pivotal role in the planet's climate. Major efforts have been made to understand how water vapor is spatially and temporally distributed over the last few decades (Montmessin et al., 2017a). Its global seasonal cycle has been studied continuously for 20 years through nadir measurements of column abundance by TES/Mars Global Surveyor (Smith, 2004), three experiments onboard Mars-Express (MEX), SPICAM (Trokhimovskiy et al., 2015), OMEGA (Maltagliati et al., 2011a) and PFS (Fouchet et al., 2007; Wolkenberg et al., 2011), and by the CRISM instrument on the Mars Reconnaissance Orbiter (MRO) (Smith et al., 2009). The global annual average abundance of water fluctuates around 10 pr. $\mu \mathrm{m}(\sim 200 \mathrm{ppm}$, assuming mixed water), increasing at high latitudes when the polar caps sublimate in spring and summer of either hemisphere. The northern hemisphere reaches its maximum in summer at $75^{\circ} \mathrm{N}$, exhibiting a column abundance of roughly $50 \mathrm{pr} . \mu \mathrm{m}$ recurrent from year to year, while the corresponding southern summer maximum is half as strong shows some interannual variability around $25 \mathrm{pr} . \mu \mathrm{m}$.

In contrast to column abundance, the climatology of water vapor vertical distribution has only been scarcely documented to date. The vertical distribution gauges multiple processes controlling the Martian water cycle, including the condensation/sublimation leading to cloud formation/collapse, the associated sedimentation and scavenging of dust particles upon which ice particles form, but also the sublimation and condensation from the polar caps, the photo dissociation and escape processes, and surface-atmosphere 
exchange (Montmessin et al., 2017a). The vertical distribution also appears to be an insightful tool for revealing the details of the Martian circulation, in particular, the massive upwards motions that permit water to access altitudes higher than $100 \mathrm{~km}$ in some extreme cases (Neary et al., 2020; Shaposhnikov et al., 2019).

By analogy with the Earth's troposphere, the vertical distribution of water on Mars is assumed to be controlled by vapor pressure, which is solely determined by temperature. The altitude level at which water vapor should condense in theory, the hygropause, rises from 10 to $20 \mathrm{~km}$ in the $\left[40^{\circ} \mathrm{S}, 80^{\circ} \mathrm{N}\right.$ ] latitude range during the colder aphelion period to $30-60 \mathrm{~km}$ in the $\left[80^{\circ} \mathrm{S}, 40^{\circ} \mathrm{N}\right]$ latitude range during the warmer perihelion period (Montmessin et al., 2004; Richardson \& Wilson, 2002a). Saturation and further condensation of water vapor at $10 \mathrm{~km}$ in northern summer is responsible for the formation of the Aphelion cloud belt (ACB), which regulates the transfer of water between hemispheres. Condensation blocks water in the northern tropics where the seasonal low-level air mass convergence turns into the rising branch of the Hadley cell (Clancy et al., 1995; Montmessin et al., 2004; Richardson \& Wilson, 2002a). The seasonal trend of saturation altitude can be inferred from column-integrated $\mathrm{H}_{2} \mathrm{O}$ measurements assuming a known temperature distribution, see, for example, Trokhimovskiy et al. (2015).

However, the concept of saturation-controlled water holding capacity is presently undermined by several lines of evidence. First, SPICAM solar occultation profiles measured in Martian Year (MY) 29 at $L s=60$ $110^{\circ}$ show considerable amounts of $\mathrm{H}_{2} \mathrm{O}$ above the hygropause, at 30-40 km (Maltagliati et al., 2011b). This water vapor, therefore, reached a supersaturated state with a pressure several times (up to 10) higher than the saturation pressure. Clancy et al. (2017) have also found strong, though indirect, hints of the persistence of supersaturation in water at $L s=60-140^{\circ}$ using as a proxy the oxygen singlet emission measured by CRISM. The full second half of MY34 $\left(L s=165-360^{\circ}\right)$ observed with atmospheric chemical suite (ACS) onboard the trace gas orbiter (TGO) shows that water vapor supersaturation is deep and ubiquitous (Fedorova et al., 2020), implying that water can be transported to the upper atmosphere much more easily than previously assumed. High degrees of supersaturation were also predicted in simulations of water ice cloud microphysics inside a Global Climate Model (Navarro et al., 2014).

Water vapor was observed at altitudes of up to 80-100 km during the global dust storms (GDSs) of 2007 (MY 28) and 2018 (MY34) with a volume mixing ratio in the 50-100 ppmv range (Aoki et al., 2019; Fedorova et al., 2018, 2020; Heavens et al., 2018; Vandaele et al., 2019). The region above $60-80 \mathrm{~km}$ is essential in the fate of water on Mars, as the thinner $\mathrm{CO}_{2}$ atmosphere no longer screens the solar UV light. Water photolysis here thus provides the main source of hydrogen atoms in the upper atmosphere, enabling their subsequent escape to space (Chaffin et al., 2017).

Variations in the Martian hydrogen escape rate by an order-of-magnitude were inferred from Lyman- $\alpha$ airglow observations during the MY28 GDS by Mars Express and the Hubble Space Telescope (Chaffin et al., 2014; Clarke et al., 2014). Photochemical modeling tied the enhanced escape rates with the presence of water molecules at 60-80 km during the GDS (Chaffin et al., 2017; Krasnopolsky, 2019). More hydrogen corona observations suggested that not only dust storms but also the perihelion season as a whole, even without a major dust event, might cause the escape rate variation (Bhattacharya et al., 2015). Instead, during perihelion and outside a GDS, significant amounts of water vapor have been observed in the southern hemisphere during MY29 $\left(L s=240-260^{\circ}\right.$ ) above $60 \mathrm{~km}$ (Maltagliati et al., 2013), and by ACS in MY34 ( $L s=270-290^{\circ}$, in between the dust events) up to $100 \mathrm{~km}$ (Fedorova et al., 2020). GCM simulations explain the seasonal upward transport of water vapor by atmospheric dynamics lifting water in the upward branch of the pole-to-pole meridional circulation cell. Shaposhnikov et al. (2019) demonstrated the upward water flux maximizes around perihelion between $L s=220^{\circ}$ and $300^{\circ}$, in a symmetric fashion about $L s=260^{\circ}$ when the global mean temperature reaches annual maximum and the circulation is the most intense because of hemispheric dichotomy (Richardson \& Wilson, 2002b). Even at this moment, the upward water flux is minimal at $\sim 60 \mathrm{~km}$, where water can penetrate into the upper atmosphere only in the region between $20^{\circ} \mathrm{S}$ and $70^{\circ} \mathrm{S}$ and transported further upward and across latitudes northward. At other seasons this flux is negligible.

Better seasonal coverage of the vertical water distribution in the lower atmosphere $(<100 \mathrm{~km})$ of Mars and of the Lyman- $\alpha$ airglow in the upper atmosphere $(>200 \mathrm{~km})$ should help disentangle the respective roles between the intense but rare GDS and the weaker but recurrent seasonal increase of dust in modulating 
the escape of hydrogen from Mars. The monitoring of water vapor profiles is also necessary to understand whether the high-altitude water, which constitutes a small fraction of the whole atmospheric water, is an essential component in the transport of water across the globe.

Here, for the first time, we present observations of $\mathrm{H}_{2} \mathrm{O}$ vertical distribution in the Martian atmosphere obtained by the SPICAM infrared spectrometer onboard Mars Express during 8 Mars years, from MY27 to MY34, including two GDS. The instrument measures the water density and mixing ratio at the Mars limb in solar occultations (Fedorova et al., 2009, 2018; Korablev et al., 2006; Montmessin et al., 2017b; Maltagliati et al., 2011b; 2013). The details of the SPICAM observations and the data analysis are described in Sections 2 and 3, respectively. The retrieved climatology is presented in Section 4, where we discuss the average data set with a focus on the second, dusty half of the Martian year, from $L s=180^{\circ}-360^{\circ}$, and the two GDS.

\section{SPICAM Observations}

SPICAM IR is an AOTF (Acousto-Optic Tunable Filter) infrared spectrometer. It works in the spectral range of 1-1.7 $\mu \mathrm{m}$ with a spectral resolution of $3.5-4 \mathrm{~cm}^{-1}$. Near the $\mathrm{H}_{2} \mathrm{O} 1.37-\mu \mathrm{m}$ band the resolving power corresponds to $\sim 2,000$. The spectrometer operates both in nadir and solar occultation modes; the present work is based on occultation data. Two detectors of the spectrometer working in orthogonal polarizations have different signal-to-noise ratios (SNR). This corresponds to $\sim 120$ in channel 0 and $\sim 220$ in channel 1 for a pure solar spectrum outside the atmosphere in the range of $1.2-1.55 \mu \mathrm{m}$. Thus we use the data of channel one for the analysis. With the FOV of $4.2 \operatorname{arcmin}\left(0.07^{\circ}\right)$ the vertical resolution in occultations varies from 1 to $12 \mathrm{~km}$ (4-5 km on average) due to the elliptical orbit of the MEX spacecraft. More details of the instrument and its calibrations related to occultations can be found in papers by Korablev et al. (2006) and Fedorova et al. (2009).

SPICAM can measure the $\mathrm{H}_{2} \mathrm{O}$ and $\mathrm{CO}_{2}$ density and the aerosol density and properties. The AOTF implies a sequential acquisition of spectra, but the measured spectral range can be arbitrarily chosen. In solar occultation we use 609 spectral points in the range of $1.34-1.47 \mu \mathrm{m}$ to record the strongest $\mathrm{CO}_{2} 1.43-\mu \mathrm{m}$ band, the $\mathrm{H}_{2} \mathrm{O} 1.37-\mu \mathrm{m}$ band and 55 points distributed between 1 and $1.7 \mu \mathrm{m}$ to measure transmission outside gaseous absorption bands ("reference wavelengths") and characterize the optical properties of aerosols (see also Fedorova et al., 2009, 2018). One spectrum is recorded in $4 \mathrm{~s}$. Taking into account that the vertical projection of the spacecraft speed on the limb varies from 0.5 to $3 \mathrm{~km} / \mathrm{s}$, the change in altitude over one spectrum varies from 2 to $10 \mathrm{~km}$ depending on occultation.

From 2005 to March of 2019 Mars Express has completed 18 occultation campaigns. Figure 1 shows the coverage of solar occultations for 8 Martian years from MY27 to MY35. This data set includes 1,500 occultations. During the two first occultation campaigns in MY27 the spectral coverage was not optimized, which meant that only the $\mathrm{H}_{2} \mathrm{O}$ density could be retrieved, but not the $\mathrm{CO}_{2}$ density. Through the whole data set, $\sim 15 \%$ of data are not suitable for the retrieval of gaseous density profiles due to pointing instabilities, problems with the reference solar spectrum, etc.

\section{Data Processing}

The details of the SPICAM IR data processing in occultations is described in Fedorova et al. (2009, 2018); Maltagliati et al. (2011b) and (2013). A summary of the retrieval process and a few recent amendments to it are presented below.

Occultation observations are self-calibrated, yielding transmittance of the atmosphere from the ratio of a spectrum through the atmosphere to the solar reference collected high enough where the atmosphere negligibly absorbs. Above $120 \mathrm{~km}$ for any season and location the $\mathrm{CO}_{2} 1.43 \mu \mathrm{m}$ absorption band is too weak to be detected by SPICAM; we therefore averaged the reference spectrum between 120 and $170 \mathrm{~km}$. Figure 2 shows an example of transmittances obtained in orbit 18560 of MY34.

Because each spectral point in an occultation spectrum is measured sequentially, each point corresponds to a different altitude. The aerosol opacity, which changes with altitude, results in an artificial spectral slope (see Figure 2). To correct it, we normalized the spectra around the studied absorption bands to the 


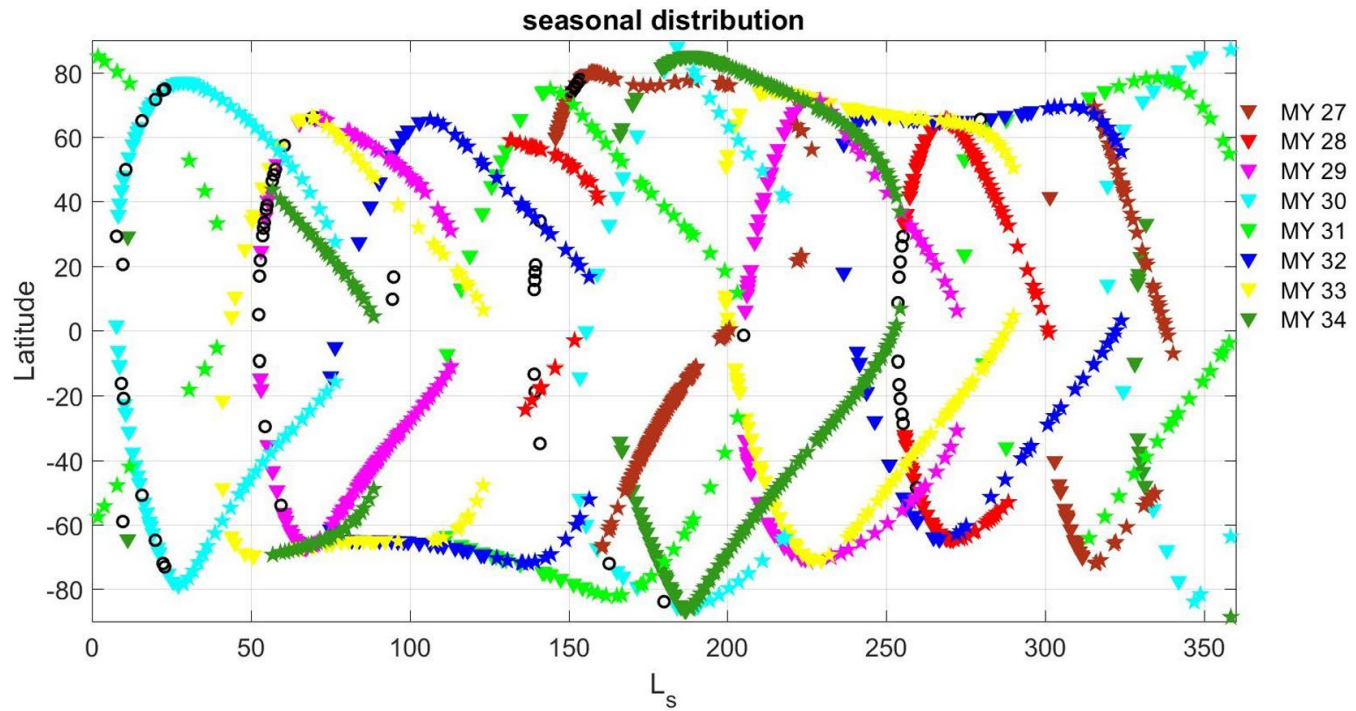

Figure 1. Seasonal-latitudinal coverage of SPICAM observations in solar occultations for 8 Martian years. The open circles mark faulty observations inapplicable for retrieval. Morning observations are marked by triangles and evening observations by stars.

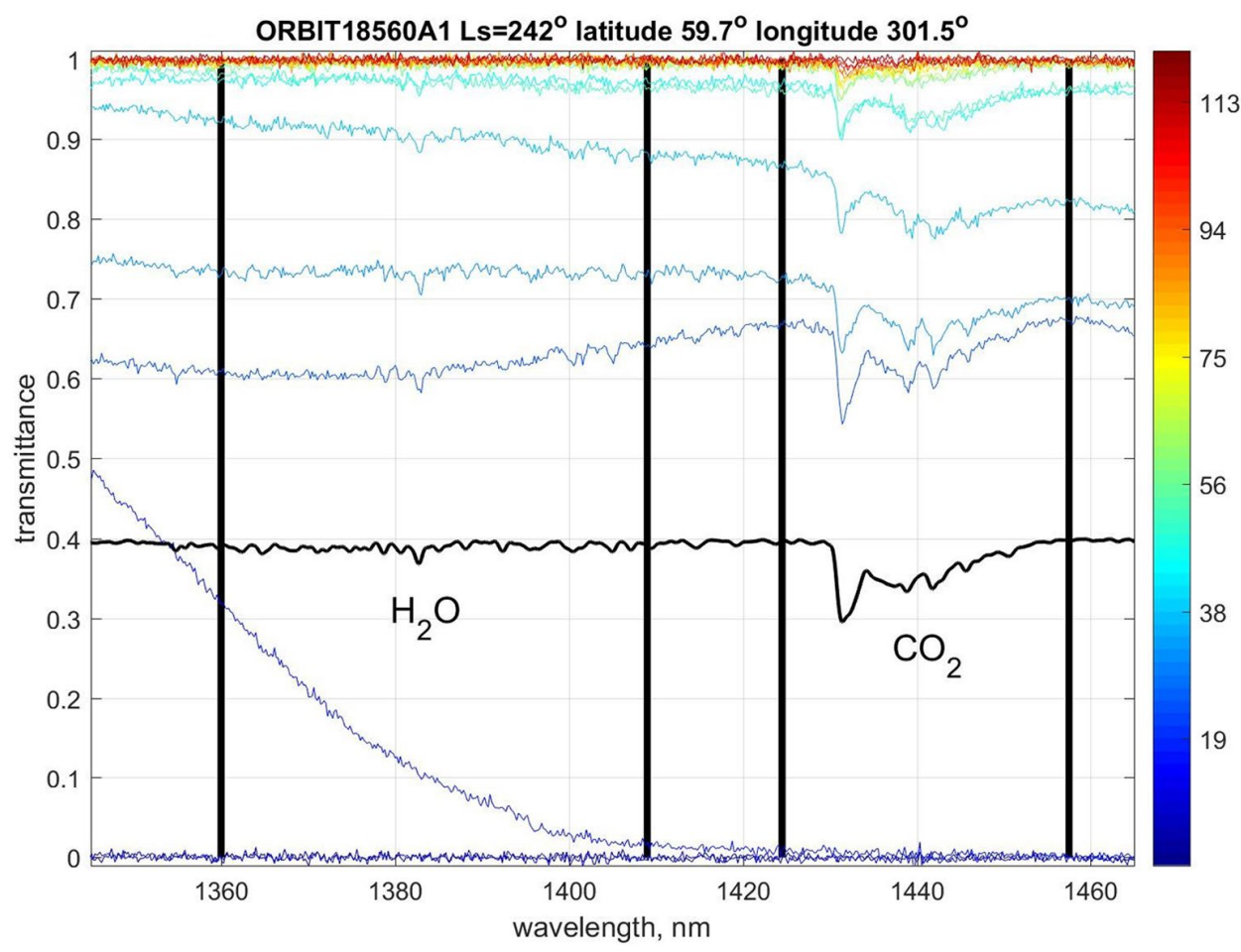

Figure 2. SPICAM transmittance spectra measured between 0 and $120 \mathrm{~km}$ for orbit $18560 \mathrm{~A} 1\left(L s=242^{\circ}, 59.7^{\circ} \mathrm{N}\right.$, $301.5^{\circ} \mathrm{E}$ ) in the spectral range of $1,346-1,462 \mathrm{~nm}$. The color indicates the average altitude of a spectrum. Data of detector one are shown. The black curve is the model spectrum with the $\mathrm{CO}_{2}$ and $\mathrm{H}_{2} \mathrm{O}$ absorption bands at the target altitude of $20 \mathrm{~km}$. Solid lines bound the spectral ranges used for the retrievals. A broad and shallow absorption appearing at 1,350-1,390 $\mathrm{nm}(\sim 0.6$ transmission level $)$ is likely a signature of a thin detached aerosol layer, manifested as a change of the slant optical depth during the spectrum record. 
continuum outside the bands. For $\mathrm{CO}_{2}$, the continuum is computed with a linear interpolation between averages of two intervals on both sides of the band, 1,423-1,426 nm and 1,456-1,459 nm. The $\mathrm{H}_{2} \mathrm{O}$ band at the short-wavelength boundary extends beyond the acquired spectral window, and the continuum is estimated in between the absorption lines within the band as described in Maltagliati et al. (2013).

To reduce the noise in measured spectra, we applied the Savitzky-Golay smoothing filter (Savitzky \& Golay, 1964) to ensure a strong noise reduction while preserving the spectral resolution. No averaging of spectra along the occultation sequence is performed, because of the too coarse vertical sampling, with typically 5-25 useful spectra during an occultation between 0 and $100 \mathrm{~km}$. We also limit the $\mathrm{H}_{2} \mathrm{O}$ fit to the strongest part of the band, between 1,360 and $1,409 \mathrm{~nm}$.

The whole profile of the local $\mathrm{H}_{2} \mathrm{O}$ or $\mathrm{CO}_{2}$ density is retrieved using the Levenberg-Marquardt iterative algorithm (Levenberg, 1944; Marquardt, 1963). The Tikhonov regularization is applied after the fit, in order to smooth the profile and minimize the errors (Ceccherini, 2005; Ceccherini et al., 2007). The uncertainty in the densities is given by the covariance matrix of the solution errors. The $\mathrm{H}_{2} \mathrm{O}$ detection limit is estimated as $7-9 \times 10^{9}$ molecules $/ \mathrm{cm}^{3}$. This detection limit corresponds to the volume mixing ratio (vmr) accuracy better than 1 ppm below $35 \mathrm{~km}$, better than $10 \mathrm{ppm}$ at 50-55 km and better than $70 \mathrm{ppm}$ at $80 \mathrm{~km}$. The measurement accuracy varies with season and location due to variations of atmospheric density. The $\mathrm{CO}_{2}$ detection limit is below $10^{12}$ molecules $/ \mathrm{cm}^{3}$ which corresponds to the pressure level of $2 \times 10^{-6}-6 \times 10^{-5} \mathrm{mbar}$. The $1.43 \mu \mathrm{m}$ absorption band is visible up to $110-115 \mathrm{~km}$ depending on location and season.

A line-by-line synthetic spectrum of gaseous absorption was calculated using the HITRAN 2012 spectroscopic database (Rothman et al., 2013). There are only a few laboratory measurements of the $\mathrm{CO}_{2}$-broadened $\mathrm{H}_{2} \mathrm{O}$ half-widths in this band for some lines (Langlois et al., 1994). Based on theoretical calculations by Gamache et al. (1995) and measurements in thermal IR by Brown et al. (2007), we correct the air-broadening half-widths for the $\mathrm{CO}_{2}$-broadening in the Martian atmosphere by multiplying by a factor of 1.7 (see also discussion in Fedorova et al., 2010). In case of occultation measurements, the Doppler broadening begins to dominate above $30-40 \mathrm{~km}$ and the sensitivity to this coefficient is minimal.

Information about the pressure and temperature profile in the Martian atmosphere is a critical aspect of SPICAM's water retrieval, to simulate spectra for the forward model, as well as to compute the mixing ratio. As described in Fedorova et al. (2018), while the retrieved $\mathrm{H}_{2} \mathrm{O}$ density is not very sensitive to the temperature profile, the $\mathrm{CO}_{2}$ density could be mistaken by a factor of 2 when the temperature deviates by as much as $50 \mathrm{~K}$. This translates into a $50 \%$ error in the water mixing ratio. For the forward model we used the temperature and pressure profiles from the recent European Martian Climate Database (EMCD) (http://wwwmars.Imd.jussieu.fr/, version MCD V5.3; Forget et al., 1999; Millour et al., 2019). To mitigate the differences between the model and the observations we choose the individual Mars years scenarios available in the MCD for MY 24 through 34, which use the observed daily dust column maps for each year to constrain the dust distributions in the model and hence reproduce observations to the greatest extent possible (Montabone et al., 2015, 2020). These scenarios reproduce the temperature profiles by year reasonably well, with inaccuracy being far below $50 \mathrm{~K}$ outside of a GDS. In the case of $\mathrm{CO}_{2}$, the density profile predicted by MCD was used as an a priori vector in the minimization procedure. For $\mathrm{H}_{2} \mathrm{O}$, we used a constant volume mixing ratio of one ppmv at all altitudes as an initial assumption. Examples of $\mathrm{H}_{2} \mathrm{O}$ fits can be found in Fedorova et al. $(2009,2018)$.

Even if individual dust scenarios of MY25, MY28, and MY34 in the MCD include the extreme global dust events, modeling of a GDS remains challenging. As shown in Fedorova et al. (2018), during the MY28 GDS a difference between MCD temperature profiles and measured MCS/MRO profiles sometimes reached $40 \mathrm{~K}$. Such a bias can be critical for our retrievals. We resolved to use MCS temperature profiles (Kleinböhl et al., 2009) close in time/space for these special cases when available. MCS measures at 03:00 and 15:00 Martian local time, out of phase with the MEX occultations, but many observations within $1^{\circ}$ of $L s$ and $2^{\circ}$ of latitude and $5^{\circ}$ of longitude could be found. The selection of the MCS data was done at local times closest to the SPICAM observations and performed additional checking using the daily temperature cycle of the MCD to find the difference between morning-evening SPICAM observations and day-night MCS profiles, as detailed in Fedorova et al. (2018). The share of available collocated MCS temperature profiles during two GDS (in MY28 and MY34) used to retrieve the $\mathrm{H}_{2} \mathrm{O}$ densities is high, reaching $90 \%$ of all observations. 


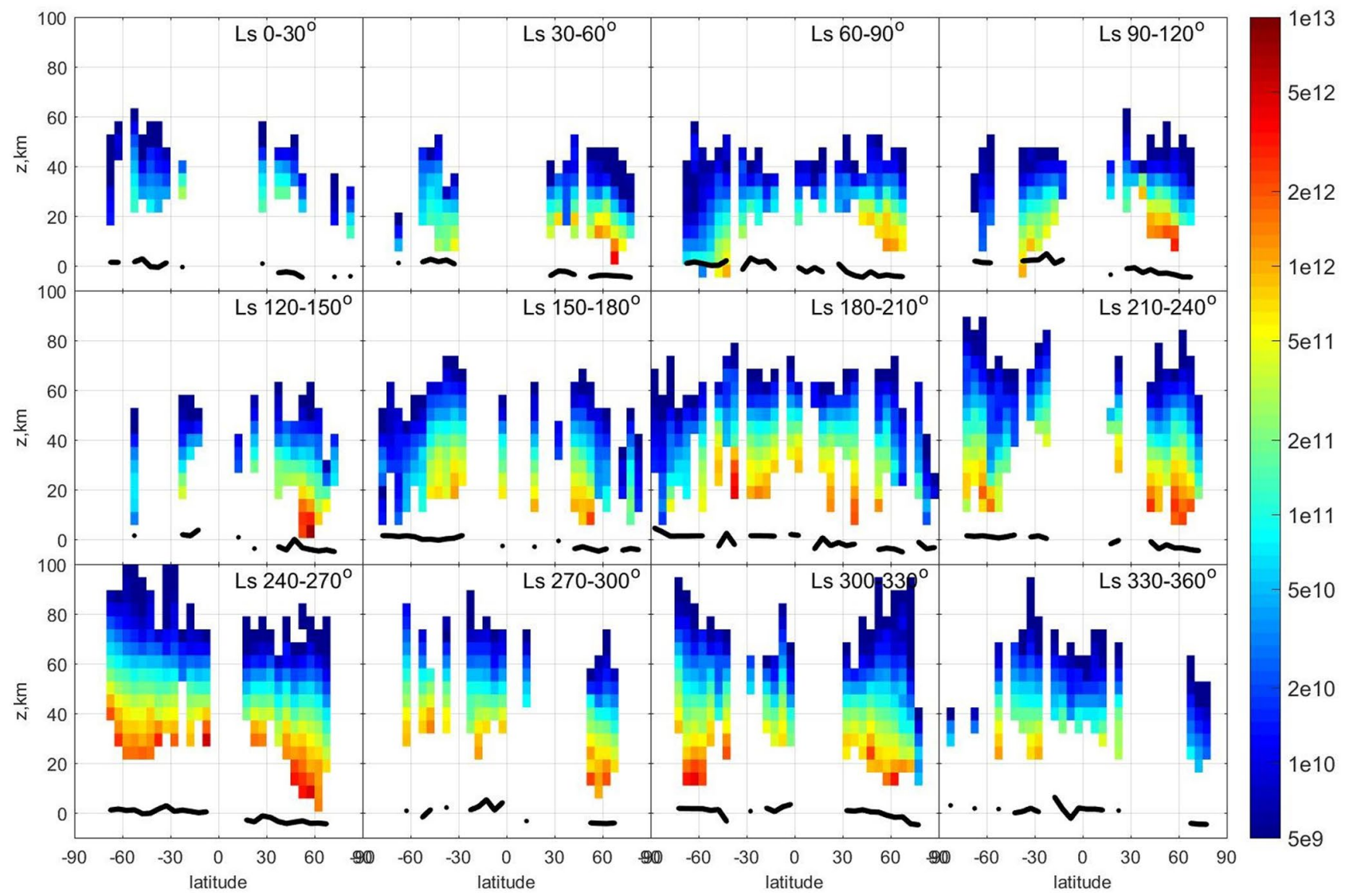

Figure 3. The $\mathrm{H}_{2} \mathrm{O}$ density distribution (in $\mathrm{cm}^{-3}$ ) with altitude and latitude for $12 \mathrm{Ls}$ bins averaged over the MY27-MY34 timeframe. The altitudes and latitudes have been arranged into $5 \mathrm{~km} \times 5^{\circ}$ bins. The data set for the global dust storm (GDS) of MY28 and 34 were excluded. The $y$-axis shows the altitude above the aroid. Black curves mark averaged MOLA altimetry for the bins.

The vertical profile of the $\mathrm{H}_{2} \mathrm{O}$ volume mixing ratio $\left(f_{\mathrm{H} 2 \mathrm{O}}\right)$ is the ratio between the water vapor number density and the atmospheric number density. To find the atmospheric density profile we divide the $\mathrm{CO}_{2}$ profile by the $\mathrm{CO}_{2}$ mixing ratio, assumed to be 0.9543 . As the $\mathrm{CO}_{2}$ and the $\mathrm{H}_{2} \mathrm{O}$ bands were not acquired at the same altitude (as described above) we find the atmospheric density at the $\mathrm{H}_{2} \mathrm{O}$ altitude with a log-linear interpolation. The error in the $\mathrm{H}_{2} \mathrm{O}$ mixing ratio is given by the quadratic sum of the uncertainties of the two density profiles. The main systematic error on $\mathrm{H}_{2} \mathrm{O}$ vmr results from the temperature profile uncertainty, in particular during the dusty part of the Martian year, due to a strong sensitivity of the $\mathrm{CO}_{2}$ band, as described above. The efforts taken to minimize this uncertainty reduce the error in the $\mathrm{H}_{2} \mathrm{O}$ vmr to $<20 \%-30 \%$. All the details of the retrieval and the associated sensitivity analysis are presented in previous works (Fedorova et al., 2009, 2018; Maltagliati et al., 2011b, 2013).

\section{Results}

\section{1. $\mathrm{H}_{2} \mathrm{O}$ Density Distribution}

The SPICAM water density profiles have been obtained for 8 Martian years from MY27 to MY34 with two occultation campaigns per year. The vertical distribution of water vapor is highly variable with season and altitude. To obtain the latitude versus altitude distribution seasonal distribution through regular years without dust storms, we averaged all observations into $12 \times 30^{\circ} \mathrm{Ls}$ bins (Figure 3) and then averaged each hemisphere separately to compare their respective $L s$ vs. altitude distributions (Figure 4). The two GDS of MY28 $\left(L s=267-302^{\circ}\right)$ and MY34 $\left(L s=190-230^{\circ}\right)$ characterized by a high elevation of water vapor are excluded from the averaged maps. 


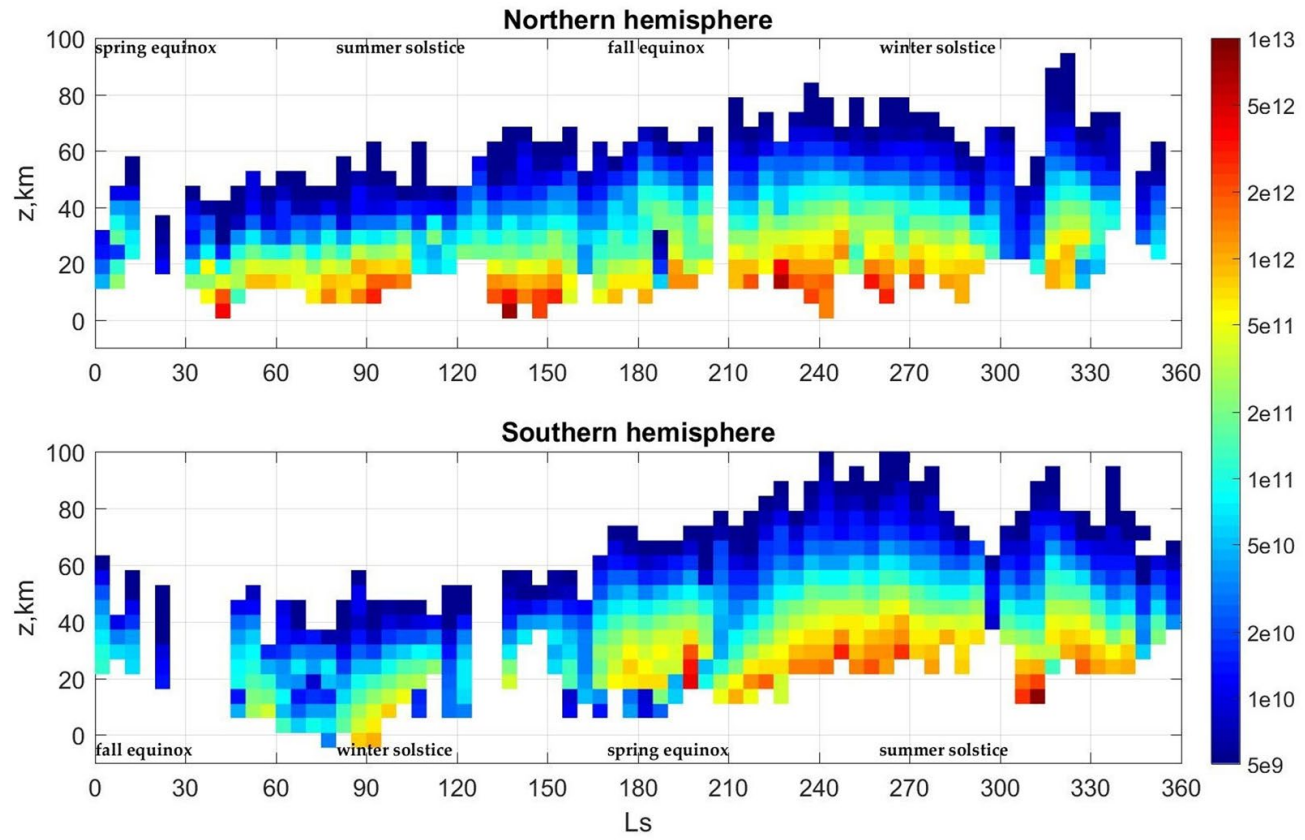

Figure 4. The $\mathrm{H}_{2} \mathrm{O}$ density distribution (in $\mathrm{cm}^{-3}$ ) with altitude as a function of $L s$ for the northern and southern hemispheres. Altitudes and Ls are arranged into $5 \mathrm{~km} \times 5^{\circ}$ bins. Two GDS of MY28 and MY34 are excluded from the binning.

The detected density varies from $5 \times 10^{9} \mathrm{~cm}^{-3}$ to $10^{13} \mathrm{~cm}^{-3}$. Water vapor is less abundant and more confined into the lower atmosphere during northern spring/summer, as expected, due to the colder aphelion climate and correspondingly the lower level of the hygropause. Noticeable amounts of water are observed at $30-40 \mathrm{~km}$, while profiles can be traced as high as $40-60 \mathrm{~km}$ in the aphelion season at $L s=30-120^{\circ}$. Around perihelion, at $L s=240-270^{\circ}$ the highest water is observed at $70-90 \mathrm{~km}$. To first order then, water transport to higher altitude is dictated by atmospheric temperature as the Aphelion-to-Perihelion transition corresponds to $>20 \mathrm{~K}$ temperature change (Smith et al., 2017).

At $L s=30-90^{\circ}$ during the northern spring-summer, the maximal water density was observed in the middle and high northern latitudes corresponding to the sublimation at the northern polar cap and subsequent water release. In the southern equinox $\left(L S=150-210^{\circ}\right)$ timeframe, the water distribution is very symmetric between the two hemispheres with low values at high latitudes. Sparse detections at $L s=0-150^{\circ}$ are explained by the confinement of the water vapor near the surface, associated with a less confined aerosol layer and Aphelion intertropical clouds that both impair detection.

Figure 5 shows the maximal altitude where the $\mathrm{H}_{2} \mathrm{O}$ density reached $10^{10}$ (close to SPICAM's detection limit, but still dependably measured). The black open circles mark orbits where no water was detected at all, meaning the density at all altitudes was below $5-7 \times 10^{9} \mathrm{~cm}^{-3}$. This happened for some of the low-latitude orbits associated with the aphelion clouds at $L s=0-150^{\circ}$. Detections are also absent at polar latitudes, poleward of $60^{\circ} \mathrm{S}$ in southern winter $\left(L s=20-180^{\circ}\right)$, and poleward of $60^{\circ} \mathrm{N}$ in northern spring $\left(L s=330-330^{\circ}\right)$ and autumn $\left(140-200^{\circ}\right)$. The $10^{10} \mathrm{~cm}^{-3}$ detection threshold altitude varies from 15 to $40 \mathrm{~km}$ (30 km on average) in the aphelion season, rising to $60-90 \mathrm{~km}$ in the perihelion season.

In contrast, the warmer southern spring appears associated with higher vertical mobility of water vapor. From $L s=210^{\circ}$ the maximum of water density moves to middle-to-high southern latitudes, marking the dissipation of the polar cap. The water amount increases after $L s=240^{\circ}$ to solstice, when the density reaches $10^{12} \mathrm{~cm}^{-3}$ above $40 \mathrm{~km}$ and water extends to $90 \mathrm{~km}$ (Figures 3 and 4). Several periods when the high-altitude water is observed in the dusty season can be identified in Figure 5. Two periods, marked by stars, are related to the GDS of MY28 and 34 at $L s=190-240^{\circ}$ and $270-300^{\circ}$, respectively. During these times, water attains altitudes up to $90 \mathrm{~km}$ in both hemispheres. A pronounced solsticial maximum at $L s=240-300^{\circ}$ 


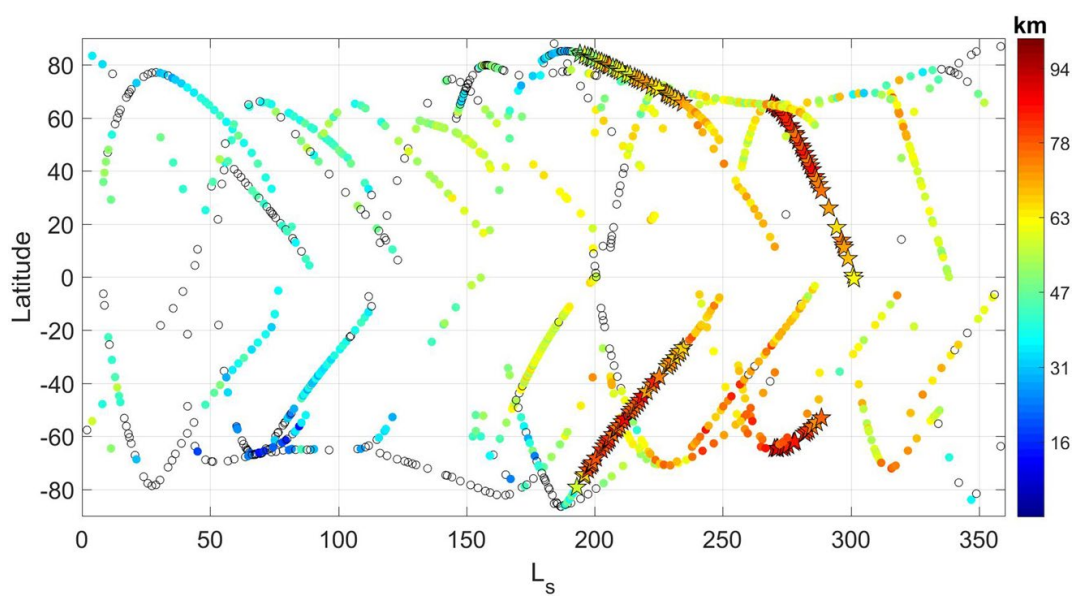

Figure 5. The altitude of water density of $10^{10} \mathrm{~cm}^{-3}$ (close to SPICAM's detection limit). Black open circles mark orbits where water is below the detection limit everywhere in the profile. Stars correspond to the global dust storm (GDS) of MY28 and MY34.

corresponds to water lofted up to $70-90 \mathrm{~km}$ in the southern hemisphere every year. In the northern hemisphere, water reaches only $60-80 \mathrm{~km}$ and thus the picture looks asymmetric around the equator in the corresponding panel of Figure 3.

We also note a moderate, compared to perihelion and GDS, increase of water up to $60-80 \mathrm{~km}$ at $L s=315-$ $330^{\circ}$ in both hemispheres (Figure 4), at least for three occultation campaigns MY27, MY31, and MY32 (Figure 5). This increase is correlated with regional dust activity, which occurs at this Ls almost every year (Kass et al., 2016). This regional dust activity started between $L s=305^{\circ}$ and $320^{\circ}$ and lasted $3-15^{\circ}$ of $L s$. Interestingly, water increased in both hemispheres in middle to high latitudes from $40^{\circ}$ to $70^{\circ}$ in accord with the recurrent northern temperature response (Kass et al., 2016). A similar increase of water was observed during the MY34 GDS by TGO (Aoki et al., 2019; Fedorova et al., 2020).

\subsection{Mixing Ratio}

Figures 6 and 7 show the $\mathrm{H}_{2} \mathrm{O}$ vmr latitude-altitude cross-sections for 12 seasonal bins and for the two hemispheres, respectively, similar to Figures 3 and 4 . In the aphelion season at $L s=30-120^{\circ}$, the $\mathrm{H}_{2} \mathrm{O}$ vmr does not exceed $40 \mathrm{ppmv}$. A minimum of water is found in middle-to-high southern latitudes during southern winter $\left(L s=60-90^{\circ}\right)$, where the vmr was below 1-2 ppmv. The confinement of water vapor toward the surface during the aphelion season suggested by the present observations (as the lowest part of the profile is inaccessible to occultation) appears in agreement with the conclusions drawn from nadir observations (Smith, 2004; Trokhimovskiy et al., 2015). Nonetheless, a sharp decrease of the mixing ratio from 50 to 55 ppmv occurs in the middle northern latitudes at $L s=30-120^{\circ}$ (the most prominent at $L s=90-120^{\circ}$ ), indicating a rise of the hygropause from $15 \mathrm{~km}$ at $60^{\circ} \mathrm{N}$ to $25-30 \mathrm{~km}$ at $40^{\circ} \mathrm{N}$.

The water mixing ratio in low-to-middle latitudes starts to grow in the middle atmosphere of both hemispheres after $L s=180^{\circ}$, reaching 50 ppmv between 20 and $60 \mathrm{~km}$. Higher northern and southern latitudes are exempt from this moistening and remain dry with vmr $\leq 5-10 \mathrm{ppmv}$. In the $L s=210-240^{\circ}$ period, humid air progressively fills all latitudes, and reaches altitudes up to $70-80 \mathrm{~km}$. The most abundant water ( $>100$ ppm) can be observed at $L s=240-270^{\circ}$ in both hemispheres, spanning the whole middle atmosphere (from 30 to $70-80 \mathrm{~km}$ ) exhibiting an uniform distribution. At high southern latitudes the water layer expands vertically higher than $90 \mathrm{~km}$. A similar pattern is observed at $L s=270-300^{\circ}$, even if our occultation data set does not cover this season well enough. The mixing ratio decreases only after $L s \sim 300^{\circ}$ in the north, as tracked by the altitude of the $10^{10}$ density level in Figure 5. However, the mixing ratio in the low-to-mid southern latitudes still reaches $50-100 \mathrm{ppmv}$ at $70 \mathrm{~km}$. Remains of the southern summer water maximum can still be spotted at low latitudes throughout the $L s=330-360^{\circ}$ period. 


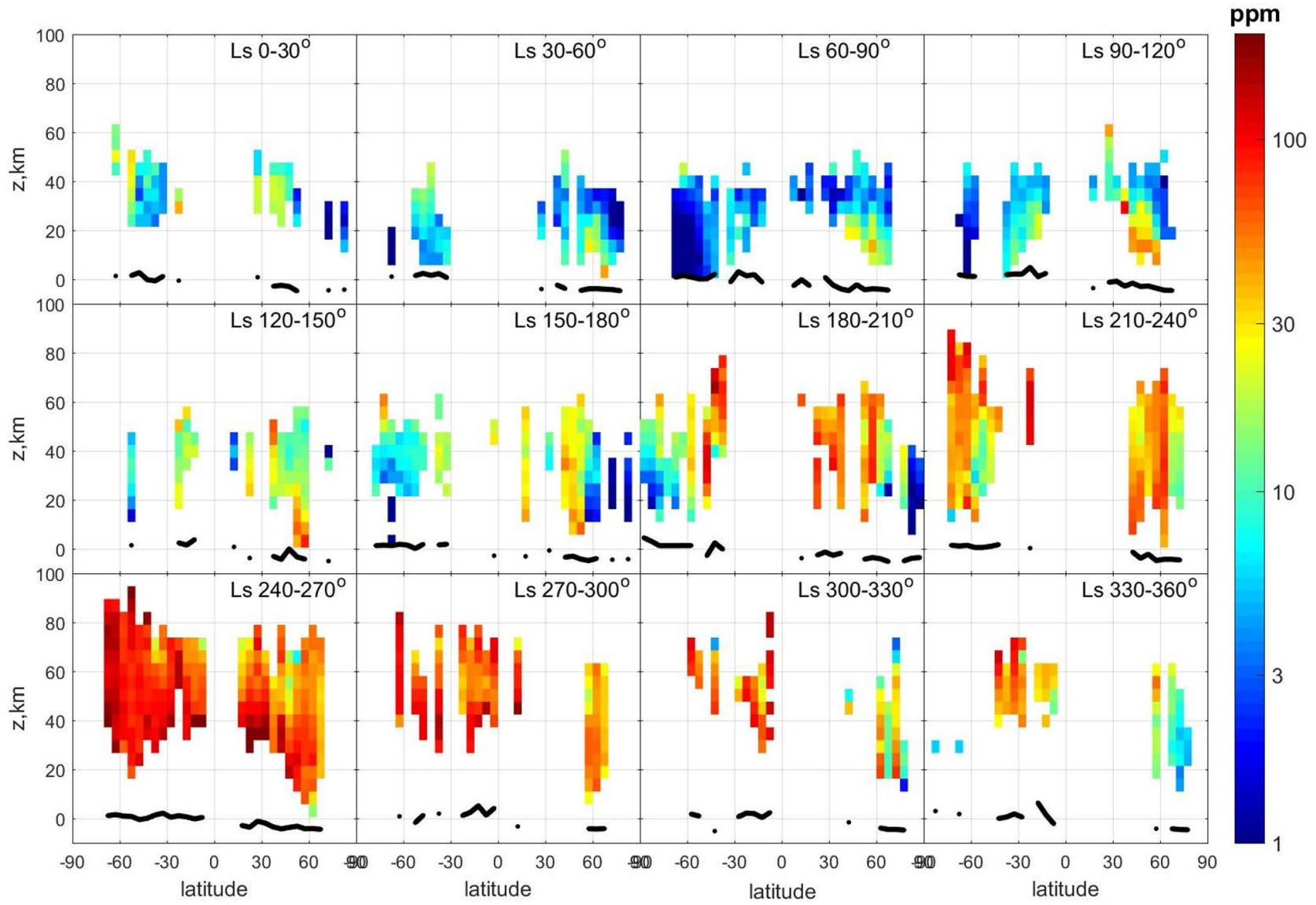

Figure 6. Same as Figure 3 except the $\mathrm{H}_{2} \mathrm{O}$ mixing ratios are displayed instead of the number density.

\subsection{Comparing Years With and Without GDS during the Dusty Season}

The SPICAM survey period includes the two GDS that happened in 2007 (MY28) and 2018 (MY34). Wang and Richardson (2015) described the development of the MY 28 GDS as observed by MARCI (MARs Color Imager) on MRO. The storm reached its global phase on $L s=269.3^{\circ}$ ( 13 sols after onset) at southern middleto-high latitudes between 35 and $80^{\circ} \mathrm{S}$ (Cantor et al., 2008). By the end of the expansion phase $\left(L s \sim 275.2^{\circ}\right.$ ), the dust encircled the planet from approximately $90^{\circ} \mathrm{S}$ to $58^{\circ} \mathrm{N}$, reaching an optical depth of 4.4-4.6 (Lemmon et al., 2015; Smith, 2009). The decay phase started at $L S \sim 310^{\circ}$ and ended at $L S \sim 310-320^{\circ}$.

The 2018 GDS has been reviewed by Guzewich et al. (2019), Montabone et al. (2020), and references therein. The storm started regionally in the northern hemisphere in the second half of May $2018\left(L S \sim 186^{\circ}\right)$ and then merged by the beginning of June $\left(L s \sim 190^{\circ}\right)$ with another regional dust lifting occurring independently in the southern hemisphere. It became global by the middle of June $\left(L s \sim 197^{\circ}\right)$. This most active period of the GDS lasted until the beginning of July $\left(L s \sim 205^{\circ}\right)$ followed by a long decay, which ended in the middle of September $\left(L s \sim 240-250^{\circ}\right)$.

The process of dust lifting was uneven across the globe for both GDS, and even at the peak of the storm northern latitudes $\left(>50^{\circ} \mathrm{N}\right)$ and southern polar areas were mostly clear of dust and suitable for solar occultations (Montabone et al., 2015, 2020). The intercomparison of the two GDS (Smith, 2019; Wolkenberg et al., 2020) showed that even though they happened in different seasons, their globally-averaged peak optical depths were similar. The MY 28 GDS reached dust optical depth greater than $1.5($ at $9 \mu \mathrm{m})$ rapidly, within $10^{\circ}-15^{\circ}$ of $L s$, and then maintained this dust loading for an extended period, before decay. According to THEMIS observations the MY 34 GDS was characterized by a more gradual build-up with a two-stage increase in dust optical depth. Dust optical depth increased rapidly at the start of the storm at the same rate 


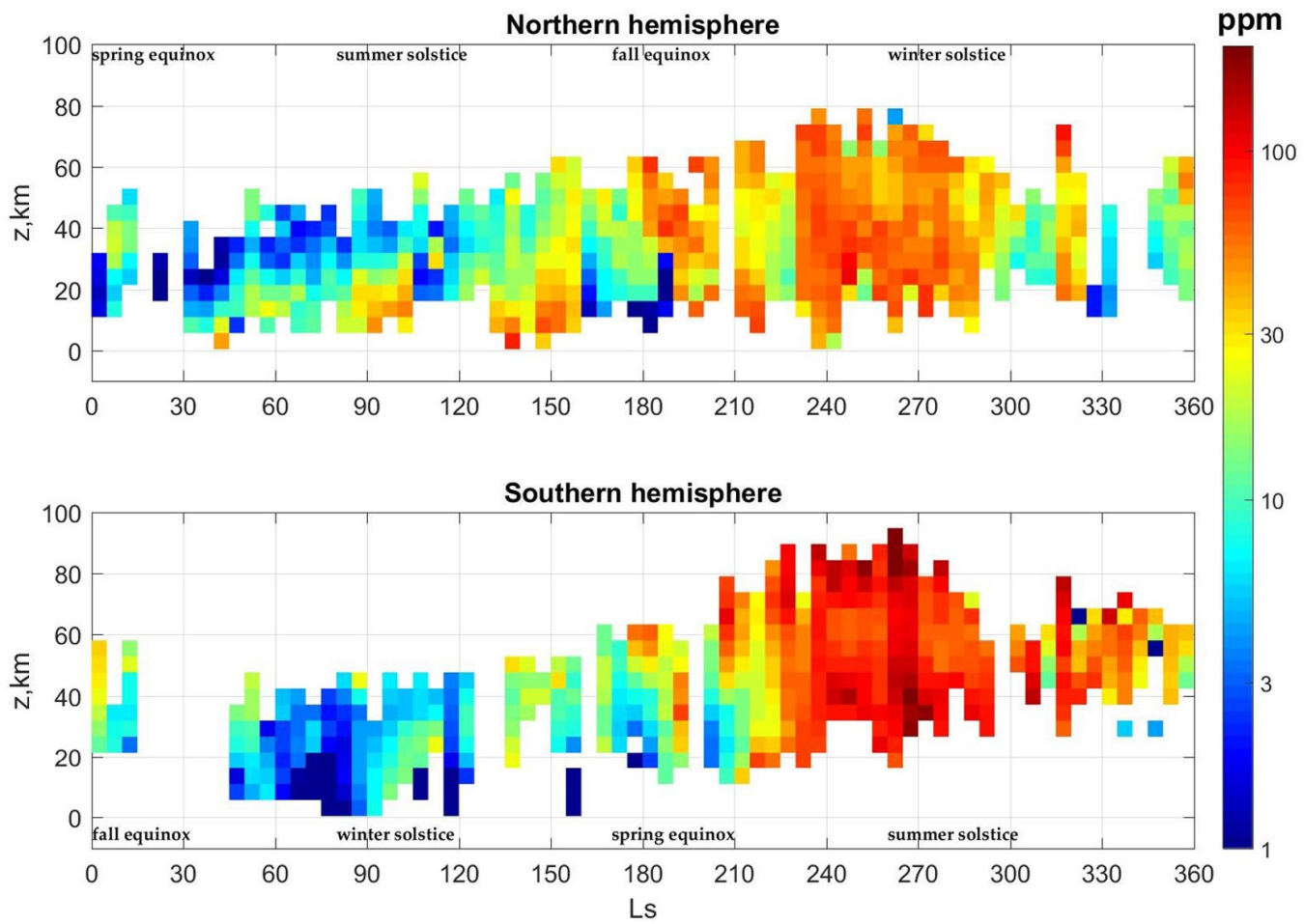

Figure 7. Same as Figure 4 except the $\mathrm{H}_{2} \mathrm{O}$ mixing ratios are displayed instead of the number density.

as during MY 28 but then remained nearly constant for several degrees of $L s$ before increasing again to its maximum value (Smith, 2019).

The water vapor distribution during MY28 was described in detail by Fedorova et al. (2018). Here, we compare the behavior of water during the two GDS, highlighting the contrast with regular perihelion seasons, unaffected by GDS. Figures 8 and 9 present the $\mathrm{H}_{2} \mathrm{O}$ density and mixing ratio distribution for altitudes of 60,70 , and $80 \mathrm{~km}$ and the lowest usable tangent height for SPICAM occultations, limited by transmission levels below this point being $<10 \%$ which corresponds to aerosol optical depth of $\sim 3$ on the line of sight and indicating the aerosol loading. In the northern hemisphere from $L s=268^{\circ}$ to $L s=285^{\circ}$ the $\mathrm{H}_{2} \mathrm{O}$ density increased by an order of magnitude at 60-80 km (Figure 8). During the dust storm, the profiles extended up to $80 \mathrm{~km}$, with a $\mathrm{H}_{2} \mathrm{O}$ mixing ratio $\geq 100 \mathrm{ppmv}$ (Figure 9). We note two maxima of the $\mathrm{H}_{2} \mathrm{O}$ density. The first and largest maximum was observed above $60^{\circ} \mathrm{N}$, from $L s=269-275^{\circ}$ and does not directly correlate with the aerosol loading. It likely relates to the downwelling branch of the meridional circulation, transporting water from the southern to the northern hemisphere, which intensified during the GDS. The second and smaller maximum at $L s=280^{\circ}$ coincides with the high dust loading at middle northern latitudes. In the South the water density at $50-80 \mathrm{~km}$ increased by a factor of $4-5$ with a mixing ratio $>100 \mathrm{ppm}$, again correlated with the aerosol extension.

During the MY34 GDS, SPICAM observations in the northern hemisphere began at very high latitudes, $>75^{\circ} \mathrm{N}$. Only from $L s=200^{\circ}$ was a water density of $>10^{10} \mathrm{~cm}^{-3}$ detected with a mixing ratio up to $100 \mathrm{ppmv}$ at altitudes of $60-70 \mathrm{~km}$ and well-correlated with increase of aerosol loading (Figure 8). Compared to the MY28 GDS, water density at $60-80 \mathrm{~km}$ was one order of magnitude lower. In the southern hemisphere, water density peaked at $10^{11} \mathrm{~cm}^{-3}$ at $70 \mathrm{~km}$, and $5 \times 10^{10} \mathrm{~cm}^{-3}$ at $60 \mathrm{~km}$, with mixing ratios of $50-100 \mathrm{ppmv}$ but still 2-3 times lower compared to MY28.

Compared to a "regular" year, $\mathrm{H}_{2} \mathrm{O}$ at $60-70 \mathrm{~km}$ during MY28 is several times more abundant in the North. In the South, high $\mathrm{H}_{2} \mathrm{O}$ density is also observed in MY29, MY32, and MY33, but still only half as large as in MY28. The density increase for the same Ls during MY34 in the southern hemisphere exceeds other years by 2-3 times, comparable with perihelion regular density, but lower than during the MY28 GDS. Despite 
(a)

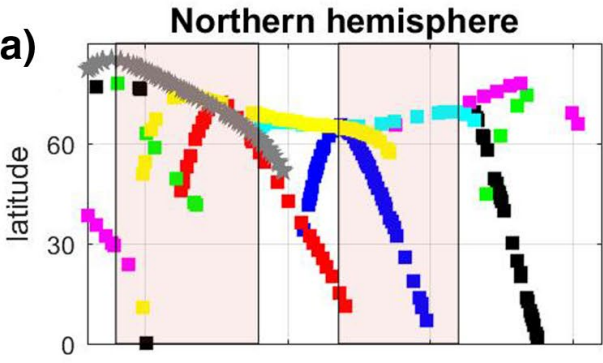

(b)

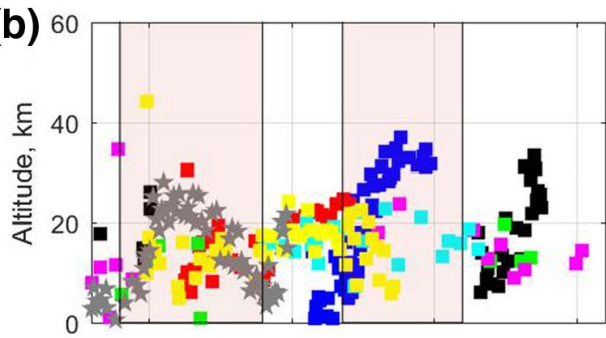

(c)

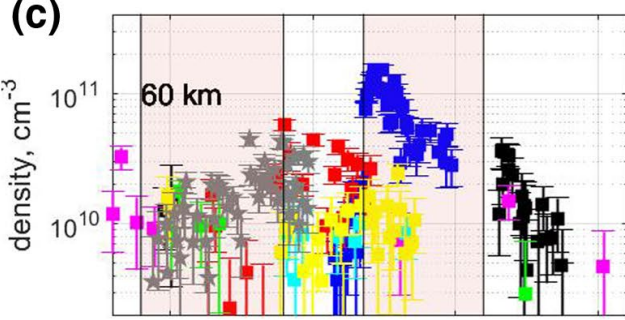

(d)

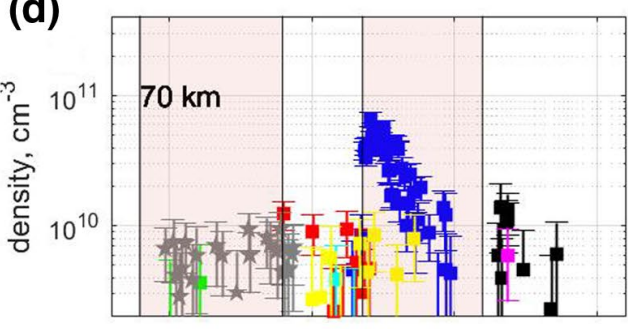

(e)

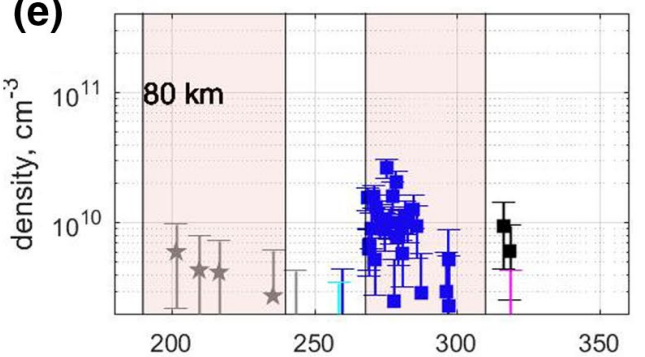

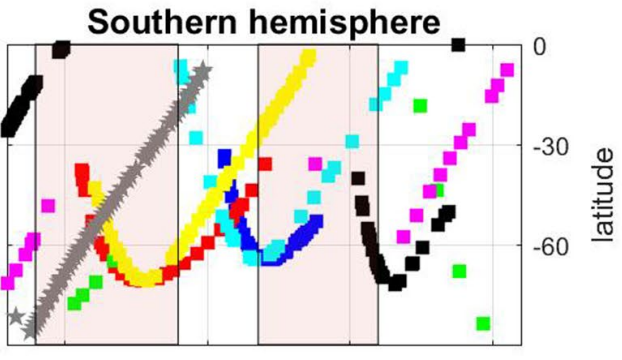
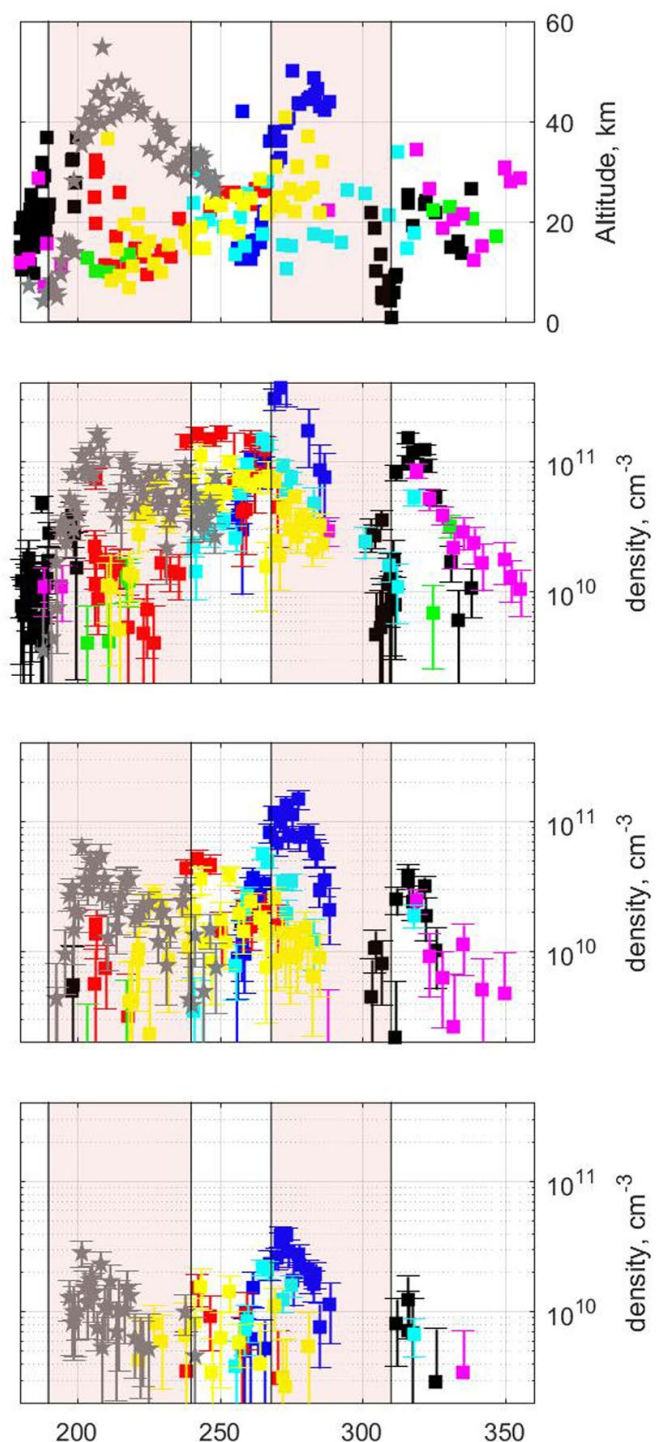

$200-250$ Ls

\begin{tabular}{llllllllllll}
\hline - MY27 & MY28 & a & MY29 & MY & MY & M & MY31 & MY 32 & MY33 & $\star$ & MY34
\end{tabular}

Figure 8. Seasonal distribution of observations for two hemispheres, (a), the lowest altitude attained in occultation (a measure of aerosol loading), (b), the $\mathrm{H}_{2} \mathrm{O}$ density at 60, 70, and $80 \mathrm{~km}$ (c, d, e, respectively) for MY27-MY34. The altitudes above the aroid are presented. The two global dust storm are marked by the pink shaded $L s$ periods. 
(a)
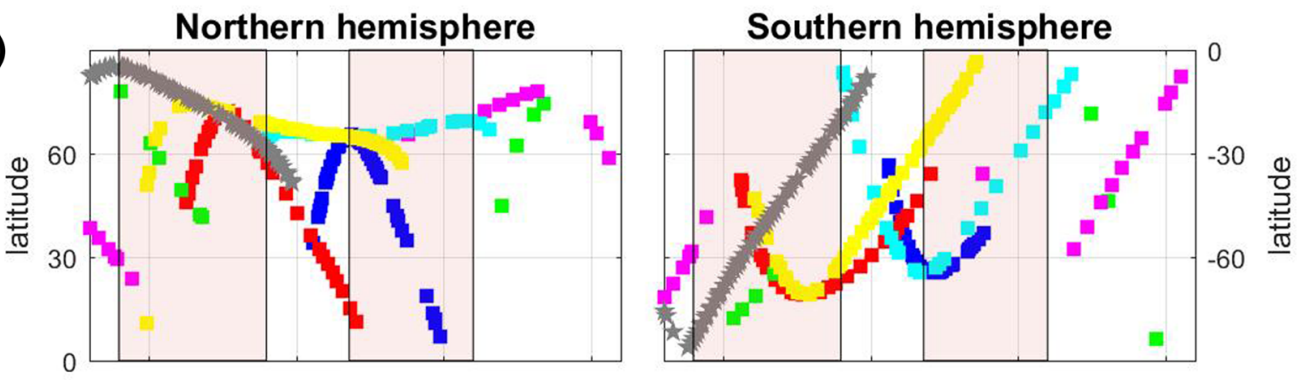

(b)
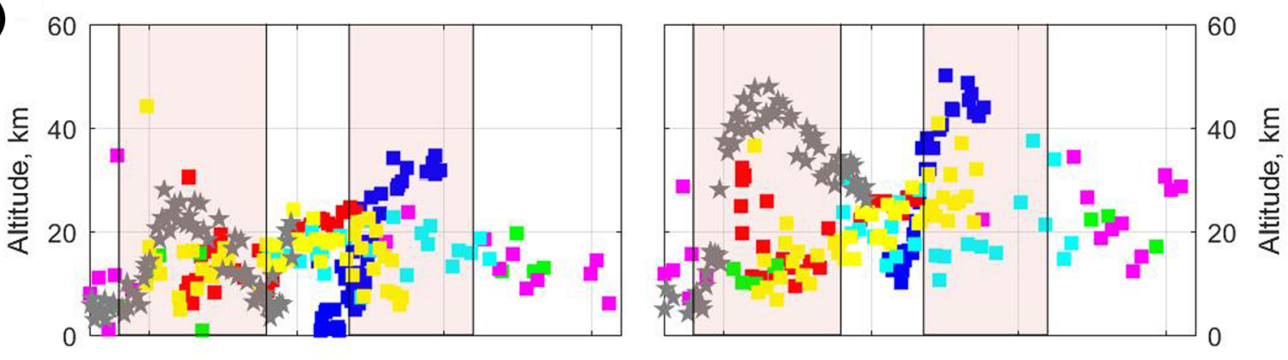

(c)
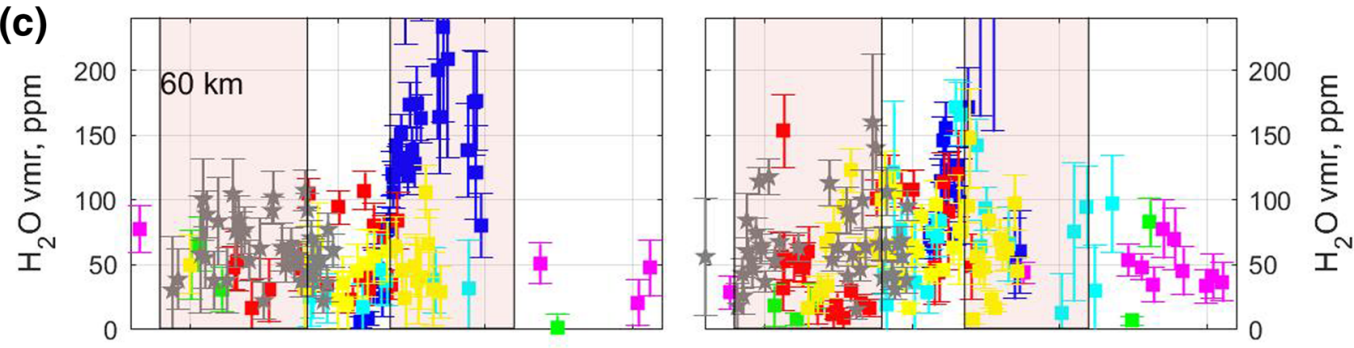

(d)
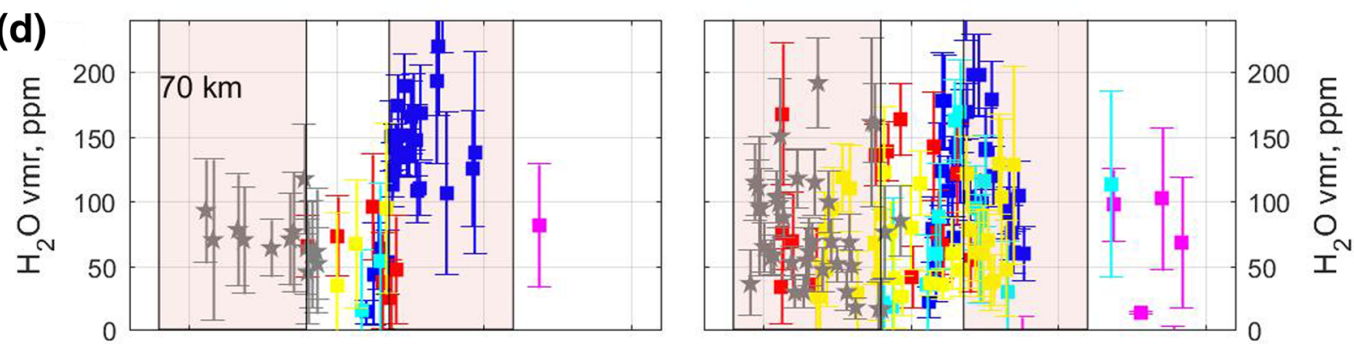

(e)
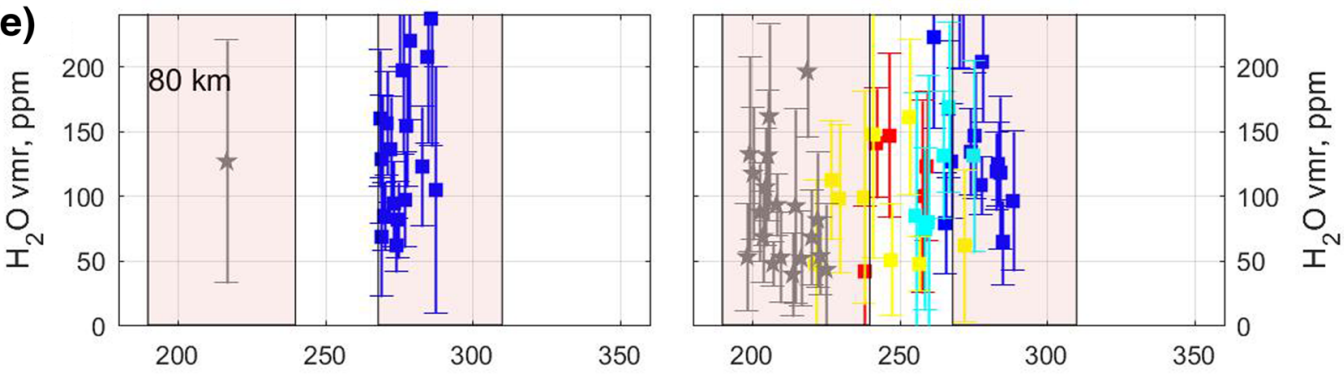

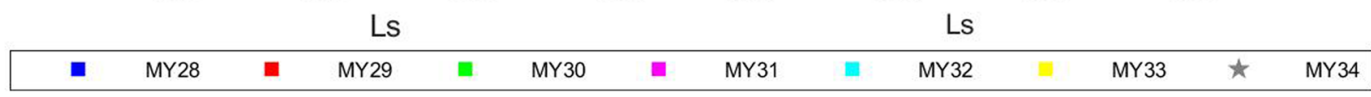

Figure 9. Same as in Figure 8 for the $\mathrm{H}_{2} \mathrm{O}$ mixing ratio for MY28-MY34. 
the observational selection, we conclude that the MY28 GDS was exceptional in terms of delivering water to high altitudes $(80 \mathrm{~km})$, exceeding at least by 2 times the perihelion water maximum and the water supply during GDS of MY34.

As one of possible explanations is the existence of a seasonal water "pump" mechanism responsible for the upward transport of water vapor suggested by Shaposhnikov et al. (2019). A combination of the mean vertical flux with variations induced by solar tides facilitates penetration of water through the condensation at $\sim 60 \mathrm{~km}$. This mechanism becomes efficient at high southern latitudes $\left(>60^{\circ} \mathrm{S}\right)$ at perihelion. That time the upward branch of the meridional circulation is particularly strong. The recent supersaturation observation in this region (Fedorova et al., 2020) even facilitates this process. Water is lifted up by the upward branch and the meridional circulation then transports it to the northern hemisphere. The GDS MY28, overlapping the upward branch of the meridional circulation that happened southern summer $L s=250-280^{\circ}$ in perihelion, made the lifting of water to extremely high altitudes and transports to middle-to-high northern latitudes.

\subsection{The MY34 GDS as Observed With SPICAM and ACS NIR Onboard TGO}

Since April 2018, two TGO infrared spectrometers (ACS and NOMAD) perform vertical profiling of water vapor. A nearly polar, not sun-synchronized circular 400-km orbit of TGO is well adapted for solar occultations which began from $L s=163^{\circ}$ of MY34. ACS and NOMAD measure the vertical distribution of $\mathrm{H}_{2} \mathrm{O}$ in several bands (Korablev et al., 2018; Vandaele et al., 2018). Aoki et al. (2019) reported the $\mathrm{H}_{2} \mathrm{O}$ distribution during the GDS and the regional storm at $L s=315-330^{\circ}$ based on NOMAD SO observations in the $2.56-\mu \mathrm{m}$ band. Fedorova et al. (2020) reported the water and temperature for the full duration of the dusty season from $L s=165^{\circ}-360^{\circ}$ with detection of supersaturation of water in this period based on ACS NIR observation in the $1.38 \mu \mathrm{m}$ band.

ACS NIR is an AOTF echelle spectrometer working in the range of 0.76-1.7 $\mu \mathrm{m}$ with spectral resolving power of 25,000-27,000 (Korablev et al., 2018). In occultation, $\mathrm{CO}_{2}$ density and temperature profiles are retrieved from 1.57- $\mu \mathrm{m} \mathrm{CO}_{2}$ band and $\mathrm{H}_{2} \mathrm{O}$ density from 1.38- $\mu \mathrm{m}$ band (Fedorova et al., 2020). Simultaneous measurement of temperature minimizes the uncertainties, discussed in Section 3 for the case of SPICAM retrievals. The vertical resolution of NIR is $\sim 1 \mathrm{~km}$, its sensitivity is better than $1 \mathrm{ppm}$ between 10 and $75 \mathrm{~km}$ and $\sim 20 \mathrm{ppm}$ at $100 \mathrm{~km}$, which surpasses the SPICAM characteristics.

In order to validate the multi-year SPICAM data set, we compare the data of SPICAM IR and ACS NIR during the MY34 GDS from $L s=160^{\circ}$ to $260^{\circ}$ in Figure 10 . The data were binned in the same manner for both experiments into $5 \mathrm{~km}$ of altitude and $5^{\circ}$ of $L s$. We note a much larger altitude range, in which the ACS profiles can be retrieved. Although the occultations as observed from the two spacecraft occur at different latitudes, the retrieved water trends are similar. Also, the retrieved values are generally close, with the exception of cases with evident latitudinal mismatch. In the northern hemisphere the increase of water to $>50$ ppm as observed by SPICAM began at $L s=195-200^{\circ}$ whereas in NIR data the growth started one bin earlier $\left(L s=190-195^{\circ}\right)$. This shift can be explained by high latitudes sounded by SPICAM at the beginning of GDS. In the southern hemisphere, both experiments show the maximum of water at $L s=200-220^{\circ}$.

\section{Conclusions}

Here we present the first multiyear survey of water vapor vertical distribution obtained from occultation measurements performed by the SPICAM spectrometer onboard the Mars Express spacecraft. The water vapor density profiles have been retrieved for 8 Martian Years MY27-MY34 and the water vapor mixing ratio for 7 Martian Years MY28-MY34, because the $\mathrm{CO}_{2}$ density reference was not measured during the first year (MY27). Data reveal seasonal and spatial variations, and the impact of two GDSs.

The detected water density varies from $5 \times 10^{9} \mathrm{~cm}^{-3}$ to $10^{13} \mathrm{~cm}^{-3}$. The upper level of detected water density is located at 40-60 km in the aphelion season and 70-90 km in the perihelion season. At $L s=30-90^{\circ}$, during the northern summer, the maximal water density was observed in the middle and high northern latitudes, corresponding to sublimation and subsequent release of vapor from the northern polar cap. Most of the aphelion detections $\left(L s=30-120^{\circ}\right)$ are located above the hygropause with $\mathrm{H}_{2} \mathrm{O}$ mixing ratio $<20$ ppmv. 

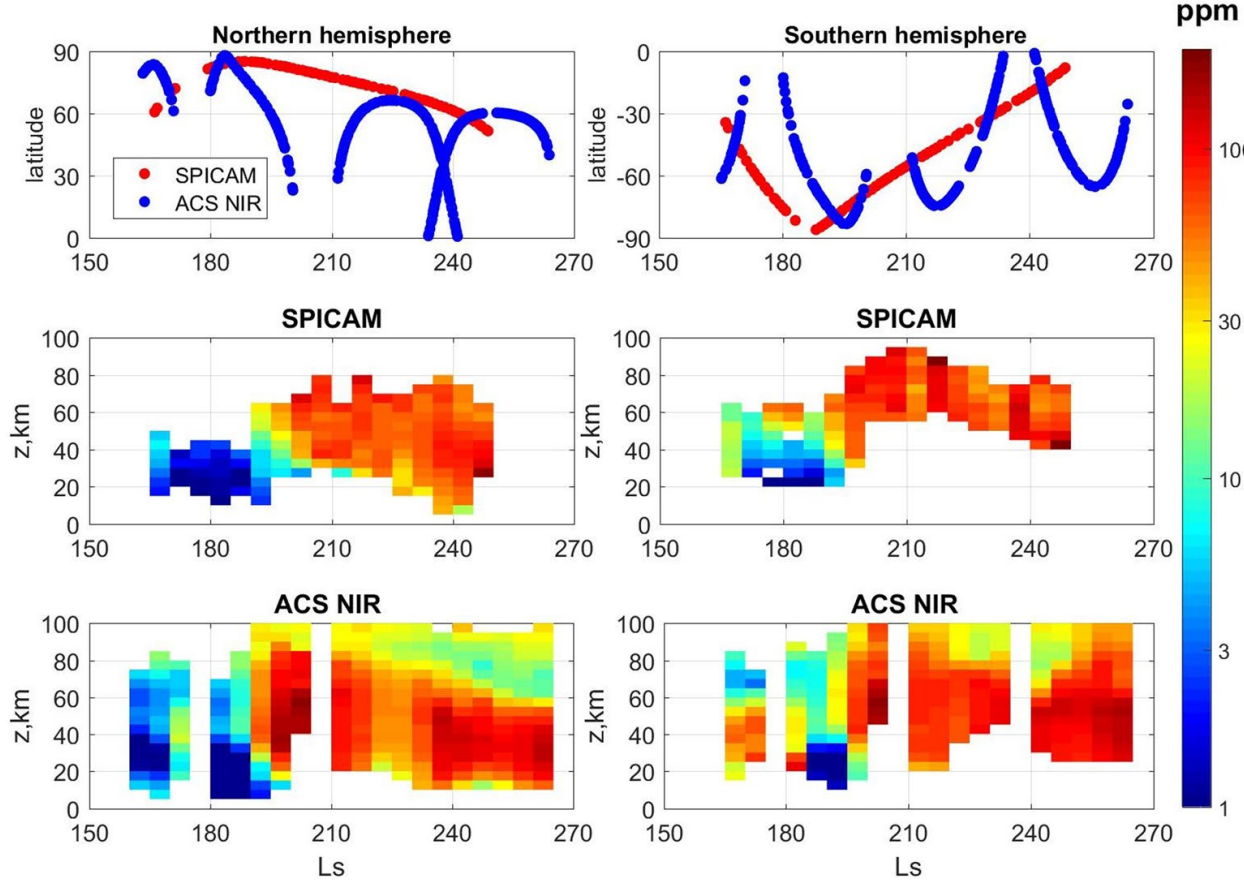

Figure 10. The comparison of SPICAM and ACS NIR observations of the MY34 global dust storm. Seasonal distribution with altitude is shown for two hemispheres. Altitudes and $L s$ are arranged into $5 \mathrm{~km} \times 5^{\circ}$ bins. Top panels: Distribution of occultations for both instruments; Middle panels: SPICAM observations; Bottom panels: ACS NIR observations.

Nevertheless, the hygropause was detected in the middle northern latitudes at $L s=30-120^{\circ}$, manifested with a sharp decrease of the mixing ratio from 50 to $55 \mathrm{ppmv}$, at the level of $15 \mathrm{~km}$ at $60^{\circ} \mathrm{N}$, to $25-30 \mathrm{~km}$ at $40^{\circ} \mathrm{N}$. Around the southern equinox, in the $L s=150-210^{\circ}$ timeframe, low water amounts are distributed symmetrically between high latitudes of both hemispheres.

The perihelion season is characterized by an increase of the water amount after $L s=240^{\circ}$ to solstice, when the density reaches $10^{12} \mathrm{~cm}^{-3}$ and mixing ratio $100 \mathrm{ppm}$ above $40 \mathrm{~km}$. Water extends to $90 \mathrm{~km}$ in the southern hemisphere confirming a seasonal impact on the hydrogen escape rate (Bhattacharya et al., 2015). In the northern hemisphere water reaches $60-80 \mathrm{~km}$ and the solstice pattern looks asymmetric. The largest mixing ratio of $>100 \mathrm{ppmv}$ at $40-90 \mathrm{~km}$ was observed at $L s=240-300^{\circ}$ in high and middle southern latitudes. At the end of the dusty season, during the regional dust activity at $L s=310-330^{\circ}$, which occurs at this $L s$ in almost every year (Kass et al., 2016), an abrupt increase of water was observed in both hemispheres in middle-to-high latitudes.

Intercomparison of water during the two GDSs of MY28 and MY34 shows that during the MY28 GDS, coincident with summer solstice $\left(L S=268^{\circ}-285^{\circ}\right)$ SPICAM observed a two-to three-fold increase of the $\mathrm{H}_{2} \mathrm{O}$ density at $60-80 \mathrm{~km}$, exceeding that in regular years and in MY34 (when this period followed a GDS), especially in the northern hemisphere. The water density increase during the MY34 GDS is comparable with the regular solstice water in the southern hemisphere. In the northern hemisphere, even though our data for MY34 sample very high latitudes only, the increase of water is prominent, marking an intensified circulation during global dust events. We conclude that the MY28 GDS was exceptional in terms of delivering water to high altitudes $(80 \mathrm{~km})$, exceeding by at least a factor of two the perihelion water maximum and the water supply during the MY34 GDS.

Comparison of SPICAM/MEX and ACS NIR/TGO observations during the MY34 GDS shows a good quantitative agreement and similar trends in both hemispheres.

The seasonal middle atmosphere water distribution presented here will help us to understand in detail the water transport between hemispheres, to study its interannual variations, and to separate the effect of 
seasonal water variation from the global and regional storm contribution, in order to quantify better the hydrogen escape from Mars.

\section{Data Availability Statement}

SPICAM raw and calibrated data are available in the ESA Planetary Science Archives (PSA) https://archives. esac.esa.int/psa/\#!Table\%20View/SPICAM=instrument. The $\mathrm{H}_{2} \mathrm{O}$ density and volume mixing ratio retrieved from the SPICAM occultation measurements are available at http://dx.doi.org/10.17632/vx4gks6bx7.1 (Fedorova, 2020). The full IR Solar Occultation Level-2B data will also be publicly available on the ESA PSA.

\begin{abstract}
Acknowledgments
SPICAM operations are funded by CNES and Roscosmos. Franck Montmessin, Franck Lefevre and Jean-Loup Bertaux acknowledges support from the Centre National d'Études Spatiales (CNES) and from the Centre National de la Recherche Scientifique (CNRS). We are grateful to our reviewers and editors whose comments helped to im prove the manuscript. Anna Fedorova, Oleg Korablev and Alexander Trokhimovskiy acknowledge the Ministry of High Education and Science of Russian Federation, for subsidy to IKI RAS.
\end{abstract}

\section{References}

Aoki, S., Vandaele, A. C., Daerden, F., Villanueva, G. L., Liuzzi, G., Thomas, I. R. et al. (2019). Water vapor vertical profiles on Mars in dust storms observed by TGO/NOMAD. Journal of Geophysical Research: Planets, 124(12), 3482-3497. https://doi.org/10.1029/2019je006109 Bhattacharya, D., Clarke, J. T., Bertaux, J. L., Chaufray, J. Y., \& Mayyasi, M. (2015). A strong seasonal dependence in the Martian hydrogen exosphere. Geophysical Research Letters, 42, 8678-8685. https://doi.org/10.1002/2015GL065804

Brown, L. R., Humphrey, C. M., \& Gamache, R. R. (2007). $\mathrm{CO}_{2}$-broadened water in the pure rotation and v2 fundamental regions. Journal of Molecular Spectroscopy, 246(1), 1-21. http://dx.doi.org/10.1016/j.jms.2007.07.010

Cantor, B. A., Malin, M. C., Wolff, M. J., Haberle, R. M, James, P. B., Clancy, R. T., \& Lee, S. W. (2008). Marci Science Team, Observations of the Martian Atmosphere by MRO-MARCI, An Overview of 1 Mars Year, Third International Workshop on The Mars Atmosphere: Modeling and Observations, held November 10-13, 2008 in Williamsburg, Virginia. LPI Contribution No. 1447, p. 9075.

Ceccherini, S. (2005) Analytical determination of the regularization parameter in the retrieval of atmospheric vertical profiles. Optics Letters, 30, 2554-2556.

Ceccherini, S., Belotti, C., Carli, B., Raspollini, P., \& Ridolfi, M. (2007). Technical Note: Regularization performances with the error consistency method in the case of retrieved atmospheric profiles. Atmospheric Chemistry and Physics, 7, 1435-1440. https://doi.org/10.5194/ acp-7-1435-2007

Chaffin, M. S., Chaufray, J.-Y., Stewart, I., Montmessin, F., Schneider, N. M., \& Bertaux, J.-L. (2014). Unexpected variability of Martian hydrogen escape. Geophysical Research Letters, 41(2), 314-320. https://doi.org/10.1002/2013GL058578

Chaffin, M. S., Deighan, J., Schneider, N. M., \& Stewart, A. I. F. (2017). Elevated atmospheric escape of atomic hydrogen from Mars induced by high-altitude water. Nature Geoscience, 10(3), 174-178. https://doi.org/10.1038/ngeo2887

Clancy, R. T., Lee, S. W., Gladstone, G. R., McMillan, W. W., \& Rousch, T. (1995). A new model for Mars atmospheric dust based upon analysis of ultraviolet through infrared observations from Mariner 9, Viking, and Phobos. Journal of Geophysical Research, 100(E3), 5251-5263. https://doi.org/10.1029/94je01885

Clarke, J. T., Bertaux, J. L., Chaufray, J. Y., Gladstone, G. R., Quemerais, E., Wilson, J. K., \& Bhattacharyya, D. (2014). A rapid decrease of the hydrogen corona of Mars. Geophysical Research Letters, 41(22), 8013-8020. https://doi.org/10.1002/2014GL061803

Fedorova, A. (2020). Water vapor on Mars from SPICAM IR occultations (MY27-34), Mendeley data. Vol. 1, https://doi.org/10.17632/ vx4gks6bx7.1

Fedorova, A., Bertaux, J. L., Betsis, D., Montmessin, F., Korablev, O., Maltagliati, L., \& Clarke, J. (2018). Water vapor in the middle atmosphere of Mars during the 2007 global dust storm. Icarus, 300, 440-457. https://doi.org/10.1016/j.icarus.2017.09.025

Fedorova, A. A., Korablev, O. I., Bertaux, J. L., Rodin, A. V., Montmessin, F., Belyaev, D. A., \& Reberac, A. (2009). Solar infrared occultation observations by SPICAM experiment on Mars-Express: Simultaneous measurements of the vertical distributions of $\mathrm{H}_{2} \mathrm{O}, \mathrm{CO}_{2}$ and aerosol. Icarus, 200(1), 96-117. http://dx.doi.org/10.1016/j.icarus.2008.11.006

Fedorova, A. A., Montmessin, F., Korablev, O., Luginin, M., Trokhimovskiy, A., Belyaev, D. A. et al. (2020). Stormy water on Mars: The distribution and saturation of atmospheric water during the dusty season. Science, 367(6475), 297-300. https://doi.org/10.1126/science. aay9522

Fedorova, A. A., Trokhimovsly, A. Y., Korablev, O., \& Montmessin, F. (2010). Viking observation of water vapor on Mars: Revision from up-to-date spectroscopy and atmospheric models. Icarus, 208(1), 156-164.

Forget, F., Hourdin, F., Fournier, R., Hourdin, C., Talagrand, O., Collins, M. et al. (1999). Improved general circulation models of the Martian atmosphere from the surface to above $80 \mathrm{~km}$. Journal of Geophysical Research, 104(E10), 24155-24175. https://doi. org/10.1029/1999je001025

Fouchet, T., Lellouch, E., Ignatiev, N. I., Forget, F., Titov, D. V., Tschimmel, M. et al. (2007). Martian water vapor: Mars Express PFS/LW observations. Icarus, 190(1), 32-49. http://dx.doi.org/10.1016/j.icarus.2007.03.003

Gamache, R. R., Neshyba, S. P., Plateaux, J. J., Barbe, A., Regalia, L., \& Pollack, J. B. (1995). $\mathrm{CO}_{2}$-Broadening of water-vapor lines. Journal of Molecular Spectroscopy, 170(1), 131-151. http://dx.doi.org/10.1006/jmsp.1995.1060

Guzewich, S. D., Lemmon, M., Smith, C. L., Martínez, G., de Vicente-Retortillo, Á., Newman, C. E. et al. (2019). Mars science laboratory observations of the 2018/Mars year 34 global dust storm. Geophysical Research Letters, 46(1), 71-79. https://doi.org/10.1029/2018gl080839

Heavens, N. G., Kleinböhl, A., Chaffin, M. S., Halekas, J. S., Kass, D. M., Hayne, P. O. et al. (2018). Hydrogen escape from Mars enhanced by deep convection in dust storms. Nature Astronomy, 2(2), 126-132. https://doi.org/10.1038/s41550-017-0353-4

Kass, D. M., Kleinböhl, A., McCleese, D. J., Schofield, J. T., \& Smith, M. D. (2016). Interannual similarity in the Martian atmosphere during the dust storm season. Geophysical Research Letters, 43(12), 6111-6118. https://doi.org/10.1002/2016GL068978

Kleinböhl, A., Schofield, J. T., Kass, D. M., Abdou, W. A., Backus, C. R., Sen, B. et al. (2009). Mars Climate Sounder limb profile retrieval of atmospheric temperature, pressure, and dust and water ice opacity. Journal of Geophysical Research, 114(E10), E10006. https://doi. org/10.1029/2009je003358

Korablev, O., Bertaux, J.-L., Fedorova, A., Fonteyn, D., Stepanov, A., Kalinnikov, Y. et al. (2006). SPICAM IR acousto-optic spectrometer experiment on Mars Express. Journal of Geophysical Research, 111(E9), E09S03. https://doi.org/10.1029/2006je002696 
Korablev, O., Montmessin, F., Trokhimovskiy, A., Fedorova, A. A., Shakun, A. V, \& Grigoriev, A. V. (2018). The Atmospheric Chemistry Suite (ACS) of Three Spectrometers for the ExoMars 2016 Trace Gas Orbiter. Space Science Reviews, 214(1). https://doi.org/10.1007/ s11214-017-0437-6

Krasnopolsky, V. A. (2019). Photochemistry of water in the Martian thermosphere and its effect on hydrogen escape. Icarus, 321, 62-70. https://doi.org/10.1016/j.icarus.2018.10.033

Langlois, S., Birbeck, T. P., \& Hanson, R. K. (1994). Temperature-Dependent Collision-Broadening Parameters of H2O Lines in the 1.4$\mu \mathrm{m}$ Region Using Diode Laser Absorption Spectroscopy. Journal of Molecular Spectroscopy, 167(2), 272-281. https://doi.org/10.1006/ jmsp.1994.1234

Lemmon, M. T., Wolff, M. J., Bell III, J. F., Smith, M. D., Cantor, B. A., \& Smith, P. H. (2015). Dust aerosol, clouds, and the atmospheric optical depth record over 5 Mars years of the Mars Exploration Rover mission. Icarus, 251, 96-111. http://dx.doi.org/10.1016/j icarus.2014.03.029

Levenberg, K. (1944). A method for the solution of certain non-linear problems in least squares. Quarterly of Applied Mathematics, 2 , 164-168.

Maltagliati, L., Montmessin, F., Fedorova, A., Korablev, O., Forget, F., \& Bertaux, J.-L. (2011b). Evidence of water vapor in excess of saturation in the atmosphere of Mars. Science, 333, 1868-1871.

Maltagliati, L., Montmessin, F., Korablev, O., Fedorova, A., Forget, F., Määttänen, A., \& Bertaux, J. L. (2013). Annual survey of water vapor vertical distribution and water-aerosol coupling in the Martian atmosphere observed by SPICAM/MEx solar occultations. Icarus, 223(2), 942-962. http://dx.doi.org/10.1016/j.icarus.2012.12.012

Maltagliati, L., Titov, D. V., Encrenaz, T., Melchiorri, R., Forget, F., Keller, H. U., \& Bibring, J.-P. (2011a). Annual survey of water vapor behavior from the OMEGA mapping spectrometer onboard Mars Express. Icarus, 213(2), 480-495. http://dx.doi.org/10.1016/j icarus.2011.03.030

Marquardt, D. (1963). An algorithm for least-squares estimation of nonlinear parameters". SIAM Journal On Applied Mathematics, 11(2), 431-441. https://doi.org/10.1137/0111030

Millour, E., Forget, F., Spiga, A., Vals, M., Zakharov, V., Montabone, L., et al., (2019). The Mars climate database (MCD version 5.3). 21st EGU General Assembly, EGU2019, id.7153. Proceedings from the conference held 7-12 April, 2019 in Vienna, Austria.

Montabone, L., Forget, F., Millour, E., Wilson, R. J., Lewis, S. R., Cantor, B. et al. (2015). Eight-year climatology of dust optical depth on Mars. Icarus, 251, 65-95. http://dx.doi.org/10.1016/j.icarus.2014.12.034

Montabone, L., Spiga, A., Kass, D. M., Kleinböhl, A., Forget, F., \& Millour, E. (2020). Martian year 34 column dust climatology from Mars climate sounder observations: Reconstructed maps and model simulations. Journal of Geophysical Research: Planets, 125, e2019JE006111. https://doi.org/10.1029/2019JE006111

Montmessin, F., Forget, F., Rannou, P., Cabane, M., \& Haberle, R. M. (2004). Origin and role of water ice clouds in the Martian water cycle as inferred from a general circulation model. Journal of Geophysical Research, 109. https://doi.org/10.1029/2004JE002284

Montmessin, F., Korablev, O., Lefèvre, F., Bertaux, J. L., Fedorova, A., Trokhimovskiy, A. et al. (2017). SPICAM on Mars express: A 10 year in-depth survey of the martian atmosphere. Icarus, 297, 195-216. https://doi.org/10.1016/j.icarus.2017.06.022

Montmessin, F., Smith, M., Langevin, Y., Mellon, M., \& Fedorova, A. (2017). The water cycle. In R. Haberle, R. Clancy, F. Forget, M. Smith, \& R. Zurek (Eds.), The atmosphere and climate of Mars (Cambridge Planetary Science, pp. 338-373). Cambridge: Cambridge University Press. https://doi.org/10.1017/9781139060172.011

Navarro, T., Madeleine, J. -B., Forget, F., Spiga, A., Millour, E., Montmessin, F., \& Määttänen, A. (2014), Global climate modeling of the Martian water cycle with improved microphysics and radiatively active water ice clouds, Journal of Geophysical Research: Planets, 119 1479-1495. https://doi.org/10.1002/2013JE004550

Neary, L., Daerden, F., Aoki, S., Whiteway, J., Clancy, R. T., Smith, M., Vandaele, A. C. (2020). Explanation for the increase in high-altitude water on Mars observed by NOMAD during the 2018 global dust storm. Geophysical Research Letters, 47(7), e2019GL084354. https:// doi.org/10.1029/2019gl084354

Richardson, M. I., \& Wilson, R. J. (2002a). Investigation of the nature and stability of the Martian seasonal water cycle with a general circulation model. Journal of Geophysical Research, 107(E5), 71-728. https://doi.org/10.1029/2001je001536

Richardson, M., \& Wilson, R. (2002b). A topographically forced asymmetry in the martian circulation and climate. Nature, 416, 298-301. https://doi.org/10.1038/416298a

Rothman, L. S., Gordon, I. E., Babikov, Y., Barbe, A., Chris Benner, D., Bernath, P. F. et al. (2013). The HITRAN2012 molecular spectroscopic database. Journal of Quantitative Spectroscopy and Radiative Transfer, 130(0), 4-50. http://dx.doi.org/10.1016/j.jpsrt.2013.07.002

Savitzky, A. \& Golay, M. J. E. (1964). Smoothing and differentiation of data by simplified least squares procedures. Analytical Chemistry. 36(8), 1627-1639. https://doi.org/10.1021/ac60214a047

Shaposhnikov, D. S., Medvedev, A. S., Rodin, A. V., \& Hartogh, P. (2019). Seasonal water "pump" in the atmosphere of Mars: Vertical transport to the thermosphere. Geophysical Research Letters, 46(8), 4161-4169. https://doi.org/10.1029/2019g1082839

Smith, M. D. (2004). Interannual variability in TES atmospheric observations of Mars during 1999-2003. Icarus, 167(1), 148-165. http:// dx.doi.org/10.1016/j.icarus.2003.09.010

Smith, M. D. (2009). THEMIS observations of Mars aerosol optical depth from 2002-2008. Icarus, 202(2), 444-452. http://dx.doi. org/10.1016/j.icarus.2009.03.027

Smith, M. D. (2019). THEMIS observations of the 2018 Mars global dust storm. Journal of Geophysical Research: Planets, 124, 2929-2944. https://doi.org/10.1029/2019JE006107

Smith, M. D., Bougher, S. W., Encrenaz, T., Forget, F. \& Kleinbohl, A. (2017) Thermal structure and composition. In R. Haberle, R. Clancy, F. Forget, M. Smith, \& R. Zurek (Eds.), The atmosphere and climate of Mars (Cambridge Planetary Science, pp. 338-373). Cambridge: Cambridge University Press.

Smith, M. D., Wolff, M. J., Clancy, R. T., \& Murchie, S. L. (2009a). Compact Reconnaissance Imaging Spectrometer observations of water vapor and carbon monoxide. Journal of Geophysical Research, 114(E2), E00D03. https://doi.org/10.1029/2008je003288

Clancy, R. T., Smith, M. D., Lefèvre, F., McConnochie, T. H., Sandor, B. J., Wolff, M. J. et al. (2017). Vertical profiles of Mars $1.27 \mu \mathrm{m} \mathrm{O}_{2}$ dayglow from MRO CRISM limb spectra: Seasonal/global behaviors, comparisons to LMDGCM simulations, and a global definition for Mars water vapor profiles. Icarus, 293, 132-156. https://doi.org/10.1016/j.icarus.2017.04.011

Trokhimovskiy, A., Fedorova, A., Korablev, O., Montmessin, F., Bertaux, J.-L., Rodin, A., \& Smith, M. D. (2015). Mars' water vapor mapping by the SPICAM IR spectrometer: Five Martian years of observations. Icarus, 251, 50-64. http://dx.doi.org/10.1016/j.icarus.2014.10.007

Vandaele, A. C., Lopez-Moreno, J. -J., Patel, M. R., Bellucci, G., Daerden, F., \& Ristic, B. (2018). NOMAD, an Integrated Suite of Three Spectrometers for the ExoMars Trace Gas Mission: Technical Description, Science Objectives and Expected Performance. Space Science Reviews, 214(80), https://doi.org/10.1007/s11214-018-0517-2 
Vandaele, A. C., Korablev, O., Daerden, F., Aoki, S., Thomas, I. R., Altieri, F., et al. (2019). Martian dust storm impact on atmospheric $\mathrm{H}_{2} \mathrm{O}$ and D/H observed by ExoMars Trace Gas Orbiter. Nature, 568(7753), 521-525. https://doi.org/10.1038/s41586-019-1097-3

Wang, H., \& Richardson, M. I. (2015). The origin, evolution, and trajectory of large dust storms on Mars during Mars years 24-30 (19992011). Icarus, 251, 112-127. https://doi.org/10.1016/j.icarus.2013.10.033

Wolkenberg, P., Giuranna, M., Smith, M. D., Grassi, D., \& Amoroso, M. (2020). Similarities and differences of global dust storms in MY 25, 28, and 34. Journal of Geophysical Research: Planets, 125(3), e2019JE006104. https://doi.org/10.1029/2019je006104

Wolkenberg, P., Smith, M. D., Formisano, V., \& Sindoni, G. (2011). Comparison of PFS and TES observations of temperature and water vapor in the Martian atmosphere. Icarus, 215(2), 628-638. https://doi.org/10.1016/j.icarus.2011.07.032 